\title{
Using Canopy Height Model Obtained with Dense Image Matching of Archival Photogrammetric Datasets in Area Analysis of Secondary Succession
}

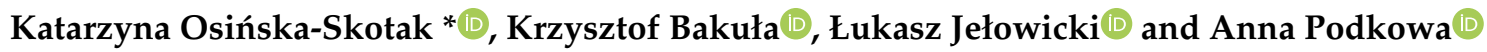 \\ Department of Photogrammetry, Remote Sensing and Spatial Information Systems, Faculty of Geodesy and \\ Cartography, Warsaw University of Technology, 00-661 Warsaw, Poland \\ * Correspondence: katarzyna.osinska-skotak@pw.edu.pl
}

Received: 26 August 2019; Accepted: 16 September 2019; Published: 19 September 2019

\begin{abstract}
One of the threats that has a significant impact on the conservation status and on the preservation of non-forest Natura 2000 habitats, is secondary succession, which is currently analyzed using airborne laser scanning (ALS) data. However, learning about the dynamics of this phenomenon in the past is only possible by using archival aerial photographs, which are often the only source of information about the past state of land cover. Algorithms of dense image matching developed in the last decade have provided a new quality of digital surface modeling. The aim of this study was to determine the extent of trees and shrubs, using dense image matching of aerial images. As part of a comprehensive research study, the testing of two software programs with different settings of image matching was carried out. An important step in this investigation was the quality assessment of digital surface models (DSM), derived from point clouds based on reference data for individual trees growing singly and in groups with high canopy closure. It was found that the detection of single trees provided worse results. The final part of the experiment was testing the impact of the height threshold value in elevation models on the accuracy of determining the extent of the trees and shrubs. It was concluded that the best results were achieved for the threshold value of $1.25-1.75 \mathrm{~m}$ (depending on the analyzed archival photos) with 10 to $30 \%$ error rate in determining the trees and shrubs cover.
\end{abstract}

Keywords: trees and shrubs succession; dense image matching; archival aerial photos; trees and shrubs extent; threats to habitats

\section{Introduction}

All of the European Union Member States are obliged to monitor the conservation status of natural habitats and species, as well as to undertake active protection measures to prevent deterioration of the status of habitats (EEA) [1]. A common (European-wide) formal methodological premise relating to the monitoring of the Natura 2000 network, is the methodology for monitoring habitats listed in Annex I of the Habitat Directive (EC) [2] at the level of the biogeographic region [3]. The currently used traditional methods of monitoring Natura 2000 habitats and identifying the main threats are based on expert assessment carried out directly on the ground. Due to the increasing potential of photogrammetric and remote sensing technologies, the availability of remote sensing sensors and airborne platforms, and the intensive development of data analysis methods (data mining, machine learning), it is reasonable to develop tools to optimize current methods of identification and assessment of the conservation status of Natura 2000 habitats.

One of the threats to non-forest Natura 2000 habitats, significantly affecting their conservation status and prospects for their preservation in Poland, is secondary succession. This is related to the gradual cessation of the use of agricultural land that has occurred since the early 1990s. Currently 
the process of secondary succession can be analyzed using airborne laser scanning (ALS) data [4,5], however, obtaining knowledge about the past dynamics of this phenomenon (e.g., from the 1960s onward) is only possible using archival materials-mainly aerial photographs, which are often the sole reliable source of information about the condition of land cover in the past.

Until now, the most common method of obtaining information on the extent of trees and shrubs based on archival aerial photographs has been photointerpretation [6-11]. Another method, albeit less frequently used in this kind of work, has been stereodigitalization [12-17]. However, both methods are highly time-consuming, and hence, the search for possibilities for automation of the process of obtaining the extent of trees and shrubs, based on these photographs. The development of digital processing algorithms and image analysis has brought a number of new possibilities in this field. Spectral classification is a frequently used solution [18,19], but because it usually requires several spectral bands, it is not a universal method and does not allow for the analysis of archival (digitized) analogue photographs (often gray scale images-panchromatic or infrared). In subsequent decades, color photographs in the optical (RGB) or color-infrared (CIR) range have become available, but they also contain only three spectral bands, which usually do not give satisfactory results in the pixel-based classification.

In the age of information technology and photogrammetry development, dense image matching (DIM) techniques could be used to automate this process. The most promising technique in recent years-semi-global matching (SGM) [20-24]—has enabled obtaining xyz point clouds, characterized by high position accuracy, based on photogrammetric images $[25,26]$. These two algorithms are often compared $[27,28]$. An attempt at description of the state-of-art in image matching and the efficiency of DSM generation, with the use of different algorithms in commercial software packages, was carried out by EuroSDR [29]. However, in the case of archival photographs, several conditions must be met in order to use these data. The previous study [30] shows that the most important aspect is the scale of the photographs, which should not be less than 1:13,000 for analogue photos, or ground sampling distance (GSD), which should be less than $25 \mathrm{~cm}$ for digital images. In addition, the date of aerial photographs acquisition has a large impact on the quality of the final product-the trees and shrubs should be fully leafed when images are collected.

In the case of analysis going back many years, when the analysis is based on archival analogue photographs, the first stage must be the digitalization of analogue photos. Correct scanning plays a large role in the context of the usefulness of archival photos for further analysis. The next step is to define exterior orientation of the images in bundle adjustment (aerotriangulation). At this stage, it is necessary to know the coordinates of control points, i.e., the signaled points in the field visible in the images. In the case of archival images, there is often a lack of such information, which may impede proper aerotriangulation [31]. The solution may be to measure characteristic points on an already-oriented model from later years, or on the ground, if it is possible to access an easily identifiable object that has not been moved over time. The very process of generating a dense cloud of points, which is then used to build a digital terrain model (DTM), can be carried out in various ways, depending on the algorithm used. There are also many types of commercial software dedicated for aerial images and for low-altitude images (e.g., Agisoft Photoscan, Pix4D, Trimble Inpho, Socet Set, LPS), as well as several open source tools (PRiME Stereo Match, MICMAC Tool, Visual SFM, StereoSGBM from the open source library OpenCV), that enable a creation of a dense cloud of points from archival photos. The algorithms implemented in them sometimes act differently, which has been the subject of many publications $[32,33]$.

In practice, for the detection of the extent of trees and shrubs, the canopy height model (CHM), which is the difference between digital surface model (DSM) and digital terrain model, is the one most commonly used [34]. In the case of entire areas, including also those that are not covered by vegetation, we can refer to a normalized digital surface model (nDSM). Then, all the areas which are above the assumed height threshold on CHM are cut off, with an assumption that the higher objects are 
vegetation. Of course, such an assumption may be adopted only for undeveloped areas. The most commonly used cut-off threshold is $2 \mathrm{~m}[21,35-38]$.

The main advantage of point clouds generated by DIM is the exact geometric description of the top surface of the stand [39]. In turn, their disadvantage is the lack of height measurements under the tree crowns level, which makes it difficult to correctly determine the height of trees. It is usually necessary to obtain DTM from another source. However, this is less important in assessing the extent of trees and shrubs, which is why, in areas characterized by flat terrain, point clouds filtering can be used to generate either DTM or ALS data, because they accurately represent the terrain in the forest areas where the variability of the terrain surface is not dynamic in time.

The main objective of our study was to assess the possibility of using digital height models, created using DIM techniques, to determine the extent of trees and shrubs, based on archival aerial photographs. As mentioned above, to determine the sites occupied by trees and shrubs, after the generation of CHM, a height threshold, above which the areas will be defined as being covered by medium and high vegetation, should be adopted. Because in the previous studies [21,35-38], forest areas have been studied and the focus has not been on the earlier stages of the secondary succession process (trees and shrubs lower than $2 \mathrm{~m}$ ), this study has attempted to analyze the impact of the CHM cut-off threshold on the effectiveness of determining the extent of the occurrence of smaller trees and shrubs. This article also analyzes the possibilities of using two types of software for point clouds generation, and consequently DSM and nDMS for vegetated areas (CHM): Agisoft Photoscan and Trimble Inpho.

In the next two sections, the study area, the methodology and the datasets used in the experiment are introduced. In the fourth section, the results of point clouds quality analysis (Section 4.1) that originate from applying various approaches and different software commonly used in vegetation monitoring are compared, with respect to ALS data, to achieve the best results of surface modeling of vegetation in the succession area. The second part of this section (Section 4.2) is the analysis of using a DSM obtained with a selected method for mapping the area of succession, considering data sources derived from DIM.

\section{Study Area}

The research was carried out in the Olsztyńsko-Mirowska Refuge, a NATURA 2000 protected area (PLH240015), which is located in the south of Poland, in the Silesian Voivodeship, near Czestochowa city $\left(50^{\circ} 45^{\prime \prime} \mathrm{N} ; 19^{\circ} 17^{\prime \prime}\right.$ E) (Figure 1). The Olsztyńsko-Mirowska Refuge is an enclave of natural and semi-natural ecosystems among the highly urbanized areas of Silesia and Czestochowa industrial districts. This area is situated entirely within the Orle Gniazda Landscape Park. The refuge includes a group of limestone hills (moors) with numerous karst forms, such as caves, monadnocks, and karst hoppers. This area is characterized by large habitat diversity. The most important habitats are non-forest habitats associated with limestone rocks with numerous, rare and endangered, thermophilic species of plants and invertebrates (including the species listed in Annex II of the Habitats Directive-the Scarce Large Blue (Phengaris teleius)). A number of species here reach the northern end of their range. In total, in the Olsztyńsko-Mirowska Refuge, there are 13 types of habitats identified in Annex I of the Habitats Directive (including 4 priority habitats) and 12 species of plants and animals listed in Annex II of the Habitats Directive [39].

The threat to the habitats of this area is primarily the process of secondary succession, which is the result of the abandonment of pastoralism, with the consequential lack of grazing and mowing of meadows, which have gradually ceased since the 1990s. In order to protect valuable habitats in the Olsztyńsko-Mirowska Refuge, under the LIFE11NAT/PL/432 project "Protection of valuable natural non-forest habitats typical of the Orle Gniazda Landscape Park" (2012-2016), a number of active protection measures have been implemented, such as grubbing of shrubs and trees and controlled sheep grazing [40]. 
The part of the Olsztyńsko-Mirowska Refuge selected for analysis covers a region which is varied in terms of terrain relief and land use, and the character of the secondary succession process, which has enabled a number of possible problems to be identified that can occur in the automation of the process of determining the extent of trees and shrubs succession. The study area encompasses an area of about $25 \mathrm{~km}^{2}$.

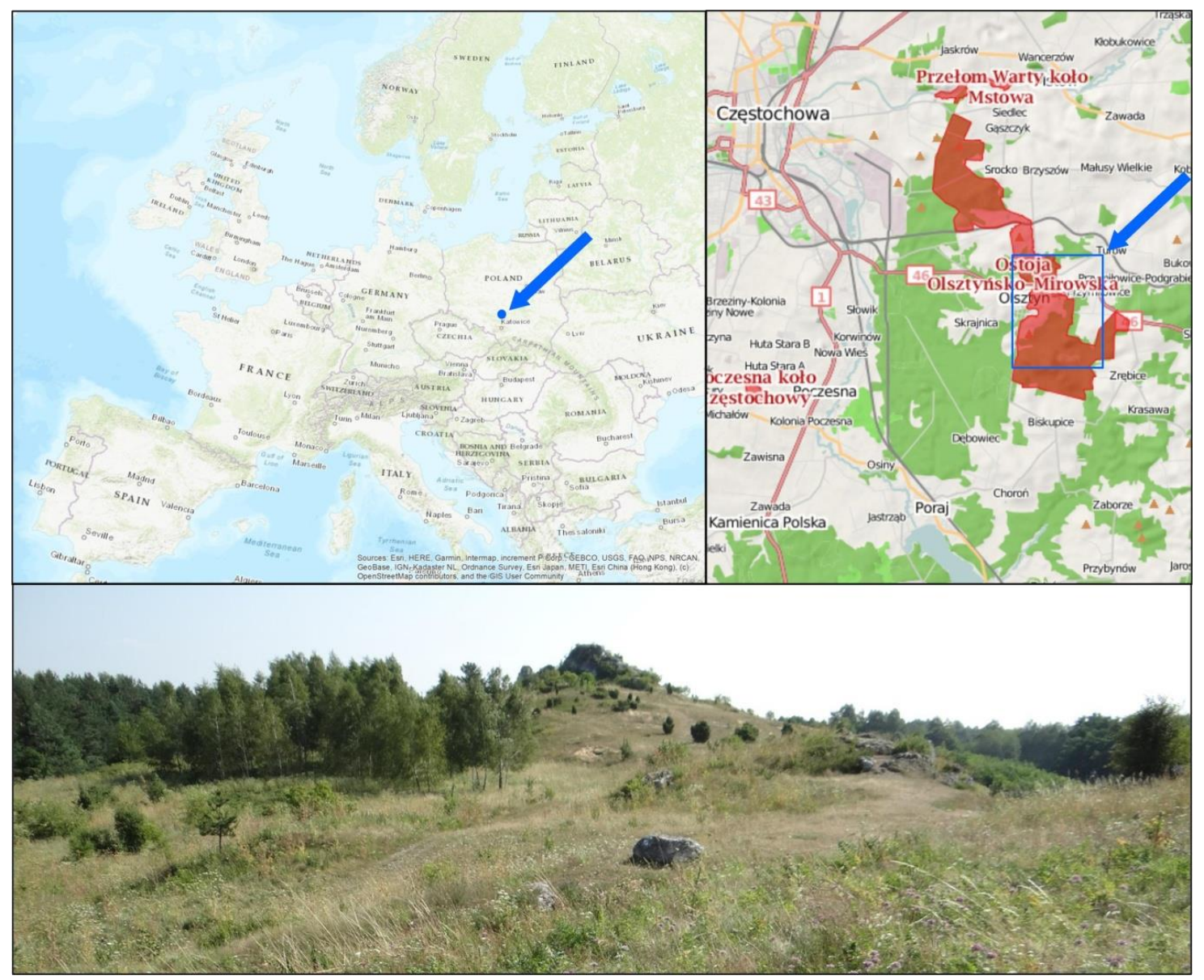

Figure 1. Location of the study area (blue rectangle) and its overview (source: http://geoserwis.gdos. gov.pl/mapy/, photo credit: B. Babczyńska-Sendek).

\section{Materials and Methods}

The main stages of the methodology included the following:

1. Analysis and selection of archival aerial photographs: These works included the query of repositories of aerial imagery and metadata describing photogrammetric projects;

2. Preparation of reference data: As part of these works, project designs were prepared, elements of the interior camera orientation (IO) and the approximate exterior orientation (EO) of aerial photographs were imported to designed projects, and coordinates of the photogrammetric control points were added for aerial triangulation in the selected reference frame;

3. Generating point clouds using the DIM algorithm: Testing the possibility of using a dense image matching in Trimble Inpho software and Agisoft Photoscan for detection in the point cloud and elevation model of individual, single trees and trees growing in compact stands, i.e., forests;

4. Preparation of final photogrammetric products: This step provided final photogrammetric products such as orthophotomaps from aerial images orthorectified with DTM from ALS datasets and DSM obtained from DIM datasets; DTM and DSMs were subsequently processed to nDSM/CHM models; 
5. Determination of the extent of trees and shrubs: Analysis of the selection of the threshold value in the CHM model to provide information on the possibilities of using current DSM from aerial photos obtained with DIM from high spatial resolution imagery for detection of vegetation succession;

6. Accuracy assessment of determining the extent of trees and shrubs compared to manually vectorized reference data.

The methodology and relations between data and products of their processing are presented in Figure 2.

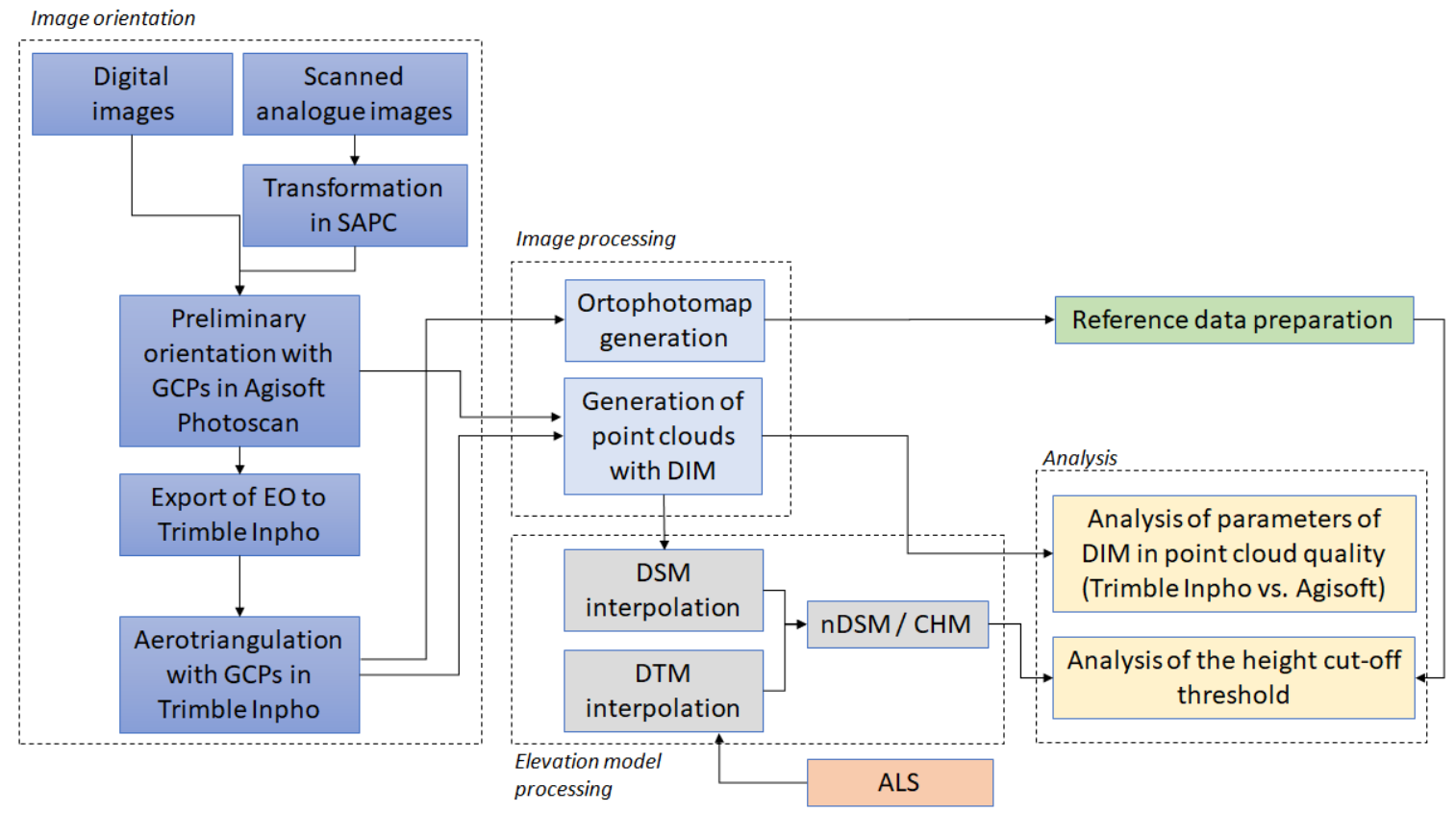

Figure 2. The methodology scheme.

\subsection{Data}

Aerial photographs from the years 1971, 1982, 1996, 2003, 2009, 2012 and 2015 were obtained from the National Geodetic and Cartographic Repository for the study area. They were both analogue and digital, black and white (panchromatic) and color (RGB). They differed in parameters, scale (from 1:13,000 to 1:32,000) or ground sampling distance, GSD (24 and $25 \mathrm{~cm}$ ) and acquisition dates (leaves-on or leaves-off phenological periods). In the case of aerial photos from 1971 and 1982, the metric features of cameras were unknown, and the radiometric quality was poor. The basic parameters characterizing all of obtained photos are presented in Table 1.

Table 1. The characteristics of aerial photographs.

\begin{tabular}{|c|c|c|c|c|c|c|c|}
\hline Date & $\begin{array}{l}\text { Numbers } \\
\text { of Photos }\end{array}$ & $\begin{array}{l}\text { GSD or } \\
\text { Scale }\end{array}$ & Camera & $\begin{array}{c}\text { Focal } \\
\text { Length }\end{array}$ & GPS/INS & $\begin{array}{l}\text { Aerotriangulation } \\
\text { (EO) }\end{array}$ & Type \\
\hline 11.08 .1971 & 12 & $1: 18,000$ & RC51 & $210.20 \mathrm{~mm}$ & $\mathrm{NO}$ & $\mathrm{NO}$ & $\mathrm{B} / \mathrm{W}$ \\
\hline 31.05 .1982 & 8 & $1: 32,000$ & $\mathrm{RC} 8$ & $114.67 \mathrm{~mm}$ & $\mathrm{NO}$ & NO & $\mathrm{B} / \mathrm{W}$ \\
\hline 30.05 .1996 & 4 & $1: 26,000$ & $\mathrm{RC} 20$ & $152.97 \mathrm{~mm}$ & $\mathrm{NO}$ & $\mathrm{NO}$ & RGB \\
\hline 24.05.2003 & 14 & $1: 13,000$ & LMK & $152.30 \mathrm{~mm}$ & NO & $\mathrm{NO}$ & $\mathrm{B} / \mathrm{W}$ \\
\hline 26.04.2009/29.04.2009 & 14 & $1: 14,000$ & RC30 & $153.81 \mathrm{~mm}$ & YES & YES & RGB \\
\hline 25.03.2012 & 10 & $24 \mathrm{~cm}$ & UltraCamXp & $100.50 \mathrm{~mm}$ & $\mathrm{NO}$ & $\mathrm{NO}$ & RGB, CIR \\
\hline 08.08 .2015 & 10 & $25 \mathrm{~cm}$ & UltraCamXp & $100.50 \mathrm{~mm}$ & $\mathrm{NO}$ & NO & RGB, CIR \\
\hline
\end{tabular}

After analyzing the parameters of available aerial photographs, it was decided that the analysis of the quality of point clouds and the possibility of detecting individual trees and trees growing in stands would be performed on all of the photographs, and the analysis of the effectiveness of determining the 
extent of trees and shrubs would be carried out for data from 1971, 1996, 2003, 2009, 2012 and 2015. Aerial photographs from 1982 were rejected due to their small scale and very low radiometric quality.

\subsection{Determination of Extent of Trees and Shrubs Using DIM}

To determine the extent of trees and shrubs based on archival data, a technique of dense image matching (DIM) was used. Different approaches for generating point clouds in two software programs: Trimble Inpho and Agisoft Photoscan were tested. In the beginning, it was necessary to prepare the input data properly, especially the archive photos. The process of archival images orientation has been described in detail in [30], where the possibility of performing a 3D analysis of succession has been considered.

Based on oriented blocks of photos in Trimble Inpho, a DIM technique was performed using the feature based matching (FBM) and area-based least square matching (LSM) algorithms in the Match-T DSM module and image matching algorithms in the Agisoft Photoscan software. Point clouds were generated with the general assumption that they should be as dense as possible, with a low level of smoothing and a high threshold of parallax. The analysis of six variants was intended primarily to test the point cloud density parameters related to the number of pixels that were used in point cloud generation. Other observed parameters were: smoothing, feature density in the FBM method preceding the LSM part of the DIM algorithm, and parallax threshold. In Agisoft Photoscan, different settings of the density parameter were tested, defined as medium and high. Analysis of the density of point clouds was aimed at enabling the capture of individual objects, such as trees, with geometry characterized by sudden changes in altitude. The image-matching algorithm worked very differently for singly growing trees starting the process of vegetation succession than for trees that have been growing for years in high canopy closure stands. To select the best set of parameters, point clouds were generated in several variants (Table 2). They were assessed considering heights in relation to current ALS data, analyzing the percentage of detected trees in the point cloud and the percentage of their height, in order to observe the vegetation growth trend that may indicate the correct height accuracy of the DSM, and consequently, CHM models. The results of this analysis are presented in Section 4.1.

Table 2. Settings of variants in generation of a point cloud in Trimble Inpho software (variants v1-v6) and Agisoft Photoscan (high and medium).

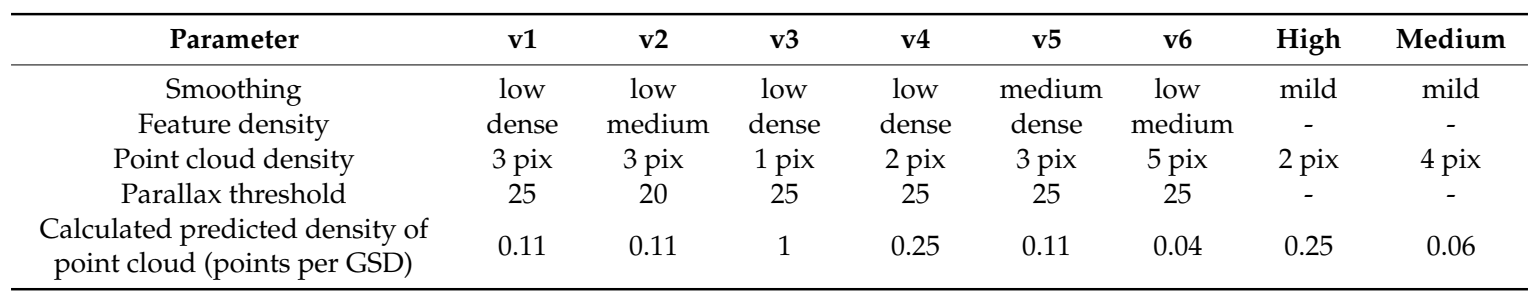

The resulting point cloud from each variant for each dataset was used for generating the DSM. This operation was performed in ArcGIS software with the following parameters: cell size of $1 \mathrm{~m} \times 1 \mathrm{~m}$, with the assumption of Baltsavias et al. [41] that sufficient point measurements of an object to be modeled should be twice as high as the GSD value. To keep height of vegetation in the elevation model, the maximum value was set as interpolation option in raster DSM (and CHM/nDSM production). As a void fill method, the natural neighbor option was selected. The determined extents of trees and shrubs were obtained from nDSM as a result of applying different height cut-off thresholds in nDSM. Different values of the height cut-off threshold were tested (1.0, 1.25, 1.5, 1.75 and $2.0 \mathrm{~m})$, and the best threshold for each of the analyzed dates was selected based on the evaluation made in comparison to the reference data. The results of this analysis are presented in Section 4.2. 


\subsection{Accuracy Assessment of the Extent of Trees and Shrubs}

The results of detailed photointerpretation of aerial orthophotomaps, prepared based on the same archival photos, were used to assess the effectiveness of determining the extent of trees and shrubs with the use of DIM algorithms. Orthophotomaps were generated with a GSD of $0.5 \mathrm{~m}$. The smallest object had a size of $2 \mathrm{~m}^{2}$, therefore it covered an area of about $3 \times 3$ pixels. Thanks to such detailed photointerpretation, it was possible at a later stage of research to show the minimum area size of trees and shrubs that can be automatically determined on the basis of individual archival materials. The area of reference masks for each date is included in Section 4.2.

The accuracy of assessment for the extent of trees and shrubs using DIM techniques was carried out using reference data prepared for each dataset. To assess the accuracy of the results, the following accuracy coefficients were used: overall accuracy (OA), recall, precision, Cohen's kappa coefficient, and F1-score [42,43]. F1-score is the harmonic mean of precision and sensitivity and is typically used as an accuracy measure of a dichotomous model [44], so it is suitable for one-class delineation. In addition, the sum of the area resulting from errors of omission and commission $(\mathrm{EO}+\mathrm{EC})$ was analyzed to show the variant with the smallest area size error.

\section{Results}

This section presents the results of assessments for DSMs derived from DIM point clouds based on reference data from ALS and evaluation of selection of threshold height values in DSM to define a reliable range of medium and high vegetation.

\subsection{Quality Assessment of the DSMs Derived from Point Clouds}

In this section, the completeness and correctness of the DSMs derived from point clouds are presented.

The analysis of the quality of the products is divided into two parts:

- the verification of the correctness of the height of individual trees, easily distinguishable in archival photographs in DIM-DSMs compared to the height recorded in the ALS data;

- the verification of the correctness of the height of individual trees growing in high canopy closure in DIM-DSMs, compared to the height recorded in the ALS data.

In order to assess the usefulness of the obtained point clouds for the delineation of trees and shrubs, the following test was carried out. For two sets of points representing vegetation, the heights were determined based on the normalized digital surface model (nDSM) obtained on the basis of DIM-DSM from several variants and DTM from ALS. The example of this analysis for both datasets is shown in Figure 3, where nDSMs and orthophotomaps are presented with some reference objects in three sets of photos with different acquisition times.

For each point (specimen), the ratio of the DIM-nDSM value in each of the examined periods to the reference value from the ALS-nDSM from laser scanning acquired in 2016, was expressed as a percentage (formula 1):

$$
\text { result }=\frac{H_{\text {tree }}(D I M-n D S M(v, d))}{H_{\text {tree }}(A L S-n D S M)} \cdot 100 \%
$$

where: $v$ —variant of DIM-nDSM, $d$-data acquisition date.

Due to the natural succession of vegetation, it is quite difficult to have reference heights from the past. It must, therefore, be assumed that with the analysis of increasingly older sets of data, the percentage of height will decrease. In this analysis, the proper result is the value indicating the existence of a specimen classified as, a) a single tree, or b) a tree in a high canopy closure.

The range of values of the reference height percentage that qualified as a positive detection of a specimen in the DIM-nDSM model is specified in Table 3. The values were selected based on data observation, as well as consultation with a research team of botanists. 

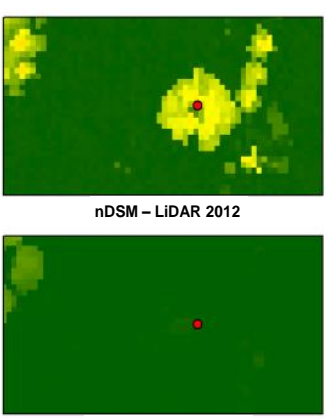

nDSM 2009, variant 3

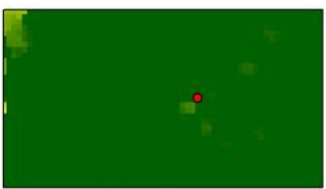

nDSM 2012, variant 3

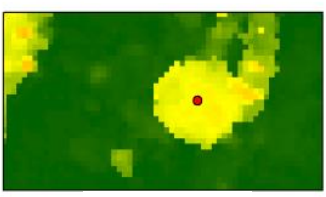

nDSM 2015, variant 3
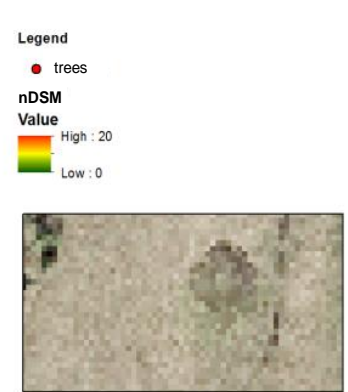

orthophoto 2009

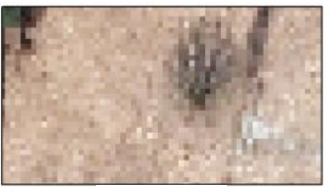

orthophoto 2012

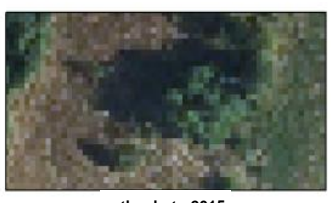

orthophoto 2015

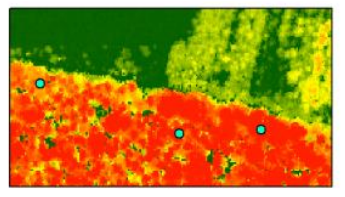

nDSM - LiDAR 2012

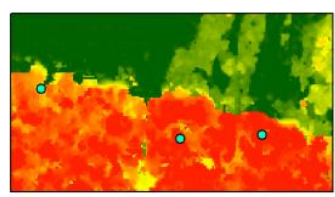

nDSM 2009, variant 3

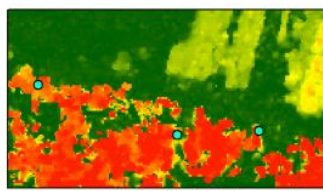

nDSM 2012, variant 3

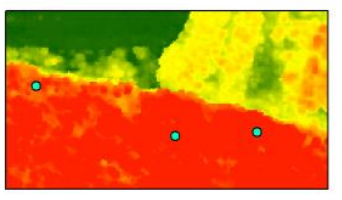

nDSM 2015, variant 3
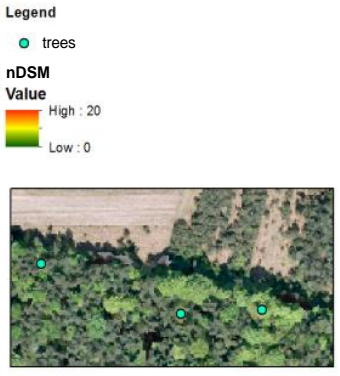

orthophoto 2009

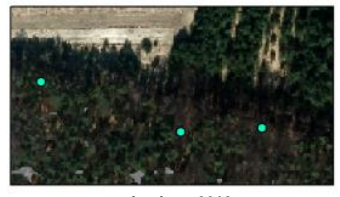

orthophoto 2012

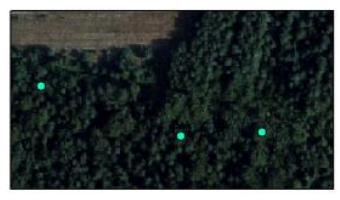

orthophoto 2015

(a)

(b)

Figure 3. Visualization of analysis of image-based normalized digital surface model (nDSM) quality using airborne laser scanning (ALS) data: reference trees (single objects (a) and trees growing in high closure (b)) are presented in nDSM and orthophotomaps from different data acquisition times.

Table 3. Assumption of height range for a positive individual tree detection, taking into account its growth without reference height in the past.

\begin{tabular}{cc}
\hline Acquisition Date & Range \\
\hline 1971,1982 & $30-110 \%$ \\
$1996,2003,2009,2012,2015$ & $50-130 \%$ \\
\hline
\end{tabular}

The analysis of the results revealed a significant variation in the obtained results. The result of tree detection based on the elevation model was not always visible, despite the tree outline being clearly noticeable on the orthophotomap (Figure 3). The results of tree detection for each date and point cloud generation variant are included in Tables A1 and A2. The visualisation of these results is presented in Figure 4. In the case of individual trees, detected based on nDSM from point clouds generated in Trimble Inpho, in the vast majority of cases the best result was given by variant v3, but the differences were very slight. This allows us to conclude that it was increasing the density of the point cloud that contributed the most to obtaining the good result. Detection values, however, range from $18 \%$ to $99 \%$ for different datasets. The date of image acquisition has the biggest impact on such a result. This is best demonstrated by the images from 2012 and 2015 having similar GSD $(24-25 \mathrm{~cm})$, acquired with the same camera (UltraCamXP). The detection results are $22 \%$ and $99 \%$, respectively, while the date of the flights is 25 March and 8 August. In March, the vast majority of deciduous trees do not usually have developed leaves and the trees' stems and branches are hardly noticeable in the image. The lighting conditions and the contrast of the objects appearing in the image also have a significant influence on the correctness of the generated point cloud, as well as the GSD/photo scale. As regards the "high" variant, in Agisoft Photoscan, it returned the same or better result than the "medium" variant for all of the years, except 2003. It also typically had a worse detection rate, by a few to several dozen percentage points, in comparison to the $\mathrm{v} 4$ variant in Trimble Inpho which was characterized by similar point cloud density. 


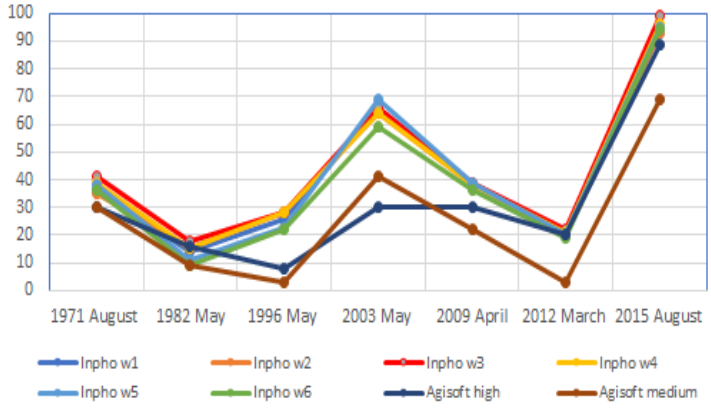

(a)

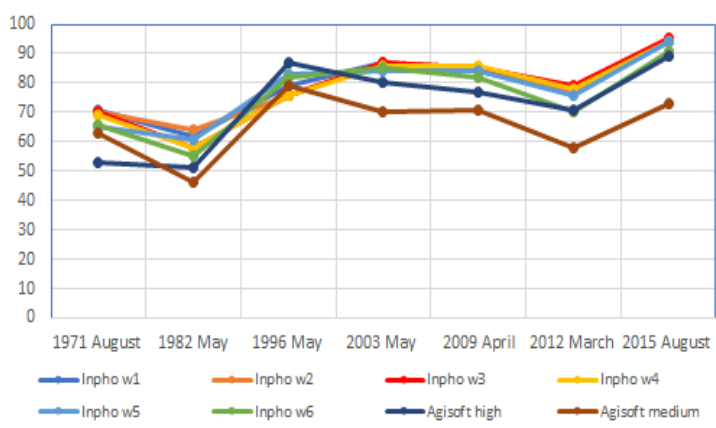

(c)

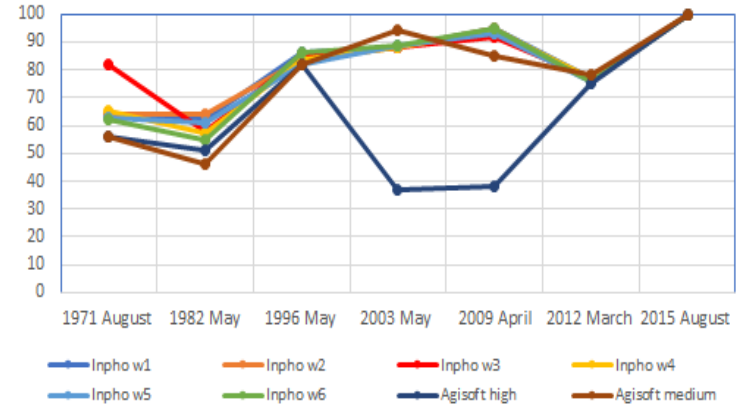

(b)

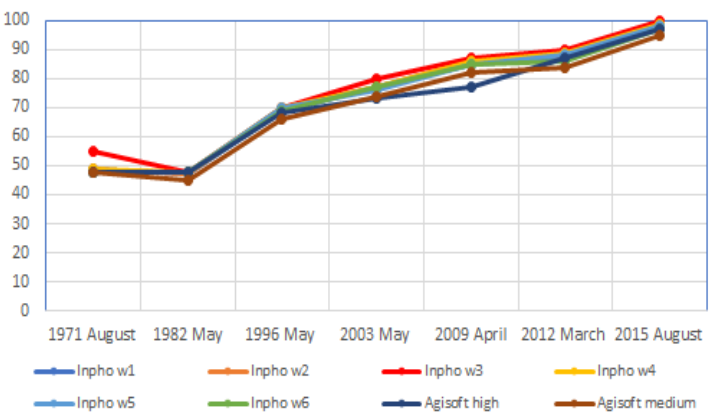

(d)

Figure 4. The results of individual trees detection (growing singly and in high closure) and estimation of average height of detected trees using dense image matching (DIM) algorithms and generated nDSM. Percent of detected trees for different settings and software for single trees (a) and for high closure tree stands (b); average height of detected trees as percent of tree height in ALS from 2016 for different settings and software for single trees (c) and for high closure tree stands (d).

In the case of trees with high canopy closure, very good results were also obtained in Trimble Inpho. Approximately 55\% to $100 \%$ of objects were qualified as properly detected, following the thresholds presented in Table 3. Variant v3 provided a much better result than the others, only for the first date of image acquisition. However, the difference was almost $20 \%$. The worst results were observed for images from 1982 and the best for 2015. The newest images allowed for a correct detection of single trees, however, v3 was the only variant that returned the average height equal to $100 \%$ of the height from ALS. Even though the v3 variant was not always the best in the detection of trees with high canopy closure, it always provided the highest average height for detected trees. For 2015, it was $100 \%$ accurate and it can be assumed that it would always be the closest to the truth, as bigger density allows for better treetop modeling.

In the case of Agisoft Photoscan software, the higher density in "high" approach did not always provide a better result. A big difference was noted in the case of high canopy closure in the images from 2003 and 2009, which can be clearly seen in Figure 4. The algorithm was not able to determine characteristic points for the larger areas of forests, with too high a resolution of the photos and many areas looking similar. As a result, the point clouds sometimes had holes in the place of forests (no data). Reducing the resolution by 4 times (the quality: "medium" instead of "high" parameter) helped to diminish this problem. Thus, one can observe the advantage of the algorithm used in Trimble Inpho over that of Agisoft Photoscan, as in the first algorithm the problem occurred on a much smaller scale.

Analyzing Figure 4, it can be seen that the detection of trees was strongly influenced by numerous factors related to image parameters or season of image acquisition. The result of trees detection in point cloud and elevation models was not easy to predict. Despite the right image parameters and the right season of image collection, fewer single trees were detected in the image from 2003 than in the 2015 image. Such a problem with the detection of trees was negligible in the case of trees growing in high canopy closure (i.e., forest, copse). Analyzing the average height of detected trees showed that 
the growing trend was much more visible for trees in high canopy closure. The trend was defined by determination coefficient of 0.92 , while for single individual trees the determination coefficient was only 0.64 in the case of v3 variant. Although these two datasets cannot be compared, due to different conditions (light availability, neighboring plants, soil, etc.), in the case of both sets, certain trends can be noticed. The problem of using dense image matching was simply its failure to detect single trees and shrubs, which is of the first signs of vegetation succession.

\subsection{Accuracy Assessment of the Extent of Trees and Shrubs for Different Threshold Values}

In order to determine the impact of the cut-off threshold on the correctness of determining the extent of trees and shrubs, threshold values of 1.0,1.25, 1.5, 1.75 and $2.0 \mathrm{~m}$ were tested. Visualizations of the results for each date for all analyzed area are presented in the figures included in the Figures A1-A5. The obtained accuracy coefficients for determining the extent of trees and shrubs for each threshold value are summarized in Table 4, and presented in Figure 5. It contains a comparison of the following metrics: overall accuracy (OA), recall, precision, Cohen's kappa coefficient and F1-score. In addition, the area size resulting from errors of omission (EO) and commission (EC) was analyzed (Table 5). A comparison of the size of these areas with reference to the trees and shrubs reference masks (in \%) is shown in Figure 6.

Table 4. The accuracy assessment of the shrubs and trees extent obtained using different thresholds.

\begin{tabular}{|c|c|c|c|c|c|c|}
\hline Threshold Value & Parameter & 1971 & 1996 & 2003 & 2009 & 2015 \\
\hline & No. of polygons & 831 & 1835 & 3580 & 4429 & 3019 \\
\hline \multirow{5}{*}{$1.0 \mathrm{~m}$} & $\mathrm{OA}$ & 0.850 & 0.833 & 0.914 & 0.902 & 0.926 \\
\hline & Recall & 0.963 & 0.854 & 0.877 & 0.774 & 0.964 \\
\hline & Precision & 0.422 & 0.522 & 0.794 & 0.923 & 0.863 \\
\hline & Cohen's kappa & 0.512 & 0.546 & 0.776 & 0.772 & 0.848 \\
\hline & F1-score & 0.587 & 0.648 & 0.833 & 0.842 & 0.911 \\
\hline \multirow{5}{*}{$1.25 \mathrm{~m}$} & $\mathrm{OA}$ & 0.872 & 0.886 & 0.919 & 0.902 & 0.936 \\
\hline & Recall & 0.958 & 0.814 & 0.865 & 0.765 & 0.955 \\
\hline & Precision & 0.461 & 0.646 & 0.816 & 0.932 & 0.890 \\
\hline & Cohen's kappa & 0.556 & 0.650 & 0.786 & 0.770 & 0.867 \\
\hline & F1-score & 0.622 & 0.720 & 0.840 & 0.840 & 0.921 \\
\hline \multirow{5}{*}{$1.5 \mathrm{~m}$} & $\mathrm{OA}$ & 0.889 & 0.911 & 0.922 & 0.901 & 0.939 \\
\hline & Recall & 0.950 & 0.781 & 0.854 & 0.756 & 0.945 \\
\hline & Precision & 0.498 & 0.739 & 0.832 & 0.939 & 0.904 \\
\hline & Cohen's kappa & 0.595 & 0.704 & 0.791 & 0.767 & 0.873 \\
\hline & F1-score & 0.653 & 0.759 & 0.843 & 0.837 & 0.924 \\
\hline \multirow{5}{*}{$1.75 \mathrm{~m}$} & $\mathrm{OA}$ & 0.903 & 0.922 & 0.923 & 0.900 & 0.942 \\
\hline & Recall & 0.934 & 0.755 & 0.844 & 0.747 & 0.937 \\
\hline & Precision & 0.535 & 0.802 & 0.844 & 0.944 & 0.916 \\
\hline & Cohen's kappa & 0.630 & 0.731 & 0.793 & 0.763 & 0.878 \\
\hline & F1-score & 0.653 & 0.778 & 0.844 & 0.834 & 0.926 \\
\hline \multirow{5}{*}{$2.0 \mathrm{~m}$} & $\mathrm{OA}$ & 0.903 & 0.927 & 0.924 & 0.898 & 0.942 \\
\hline & Recall & 0.886 & 0.734 & 0.833 & 0.740 & 0.928 \\
\hline & Precision & 0.588 & 0.842 & 0.854 & 0.948 & 0.924 \\
\hline & Cohen's kappa & 0.663 & 0.742 & 0.793 & 0.760 & 0.878 \\
\hline & F1-score & 0.707 & 0.748 & 0.844 & 0.831 & 0.926 \\
\hline
\end{tabular}

As a result of the analysis of the calculated parameters of accuracy and the visual assessment of the extent of trees and shrubs obtained for each variant of the height cut-off threshold, there was no compliance of the formal assessment and visual assessment. The largest problem were the areas of rocky outcrops and inliers, which were incorrectly detected as trees and shrubs, which resulted in difficulties of indicating the optimal cut-off threshold value. Therefore, it was decided to reassess the accuracy of 
determining the extent of trees and shrubs after excluding these problematic areas. The comparison of results for both variants is presented in the form of graphs in Figure 5. Their analysis shows that the obtained accuracy increases for the subsequent analyzed threshold values and this is true for each of the archival materials examined, with the exception of the photographs from 2009, which were acquired in the leafless period. The cut-off threshold providing the best results depends on the date (parameters and quality) of the analyzed archival materials. The greatest influence of the threshold values on the accuracy of the extent of trees and shrubs determination was observed in older photographs from 1971 (BW, 1:18,000) and 1996 (RGB, 1:26,000), where significant overestimation of trees and shrubs areas is visible. For photographs from 1971, the OA varies in the range of 0.850-0.903, kappa 0.512-0.663, F1-score 0.587-0.707, and for data from 1996, the OA varies in the range of 0.833-0.927, kappa $0.546-0.742$, and F1-score from 0.648 to 0.748 . The highest accuracy was obtained with $1.75 \mathrm{~m}$ and $2 \mathrm{~m}$ thresholds (Figure 5). For both of these thresholds, the smallest area of erroneously detected trees and shrubs was also recorded (Figure 6).

With regard to photographs from 2003 (RGB, 1:13,000) and 2009 (RGB, $24 \mathrm{~cm}$ ), it can be seen that OA, kappa and F1-score are at a similar level for all the threshold values (respectively for 2003 OA: 0.914-0.924, kappa: 0.776-0.793, F1-score: 0.833-0.844, for 2009 OA: 0.898-0.902, kappa: 0.760-0.772, F1-score: 0.831-0.842). However, the smallest area of erroneously detected trees and shrubs was obtained only for the threshold of above $1.5 \mathrm{~m}$ for data from 2003, and below $1.25 \mathrm{~m}$ for data from 2009 . Analyzing the results obtained on the basis of the latest data from 2015, it was found that OA, kappa, F1-score assume values at a similar level starting from the cut-off threshold of $1.25 \mathrm{~m}$ (OA: 0.936-0.942, kappa: 0.867-0.878, F1-score: 0.921-0.926). The smallest area size of incorrectly detected trees and shrubs was found at the $1.75 \mathrm{~m}$ threshold.

Table 5. Area of omission (EO) and area of commission (EC) (in hectares) obtained for various threshold values (excluding rocky outcrops and inliers).

\begin{tabular}{ccccccc}
\hline Threshold Value & Parameter & $\mathbf{1 9 7 1}$ & $\mathbf{1 9 9 6}$ & $\mathbf{2 0 0 3}$ & $\mathbf{2 0 0 9}$ & $\mathbf{2 0 1 5}$ \\
\hline \multirow{3}{*}{$1.0 \mathrm{~m}$} & EO & 0.43 & 3.13 & 3.70 & 9.21 & 1.64 \\
& EC & 15.66 & 12.24 & 5.46 & 1.70 & 5.73 \\
& EO + EC & 16.09 & 15.37 & 9.16 & 10.91 & 7.37 \\
\hline \multirow{3}{*}{$1.25 \mathrm{~m}$} & EO & 0.49 & 4.02 & 4.06 & 9.62 & 2.05 \\
& EC & 13.13 & 6.76 & 4.75 & 1.50 & 4.53 \\
& EO + EC & 13.62 & 10.78 & 8.81 & 11.12 & 6.58 \\
\hline \multirow{3}{*}{$1.5 \mathrm{~m}$} & EO & 0.58 & 4.77 & 4.39 & 9.99 & 2.51 \\
& EC & 11.04 & 4.08 & 4.24 & 1.35 & 3.87 \\
& EO + EC & 11.62 & 8.85 & 8.63 & 11.34 & 6.38 \\
\hline \multirow{3}{*}{$1.75 \mathrm{~m}$} & EO & 0.79 & 5.34 & 4.70 & 10.33 & 2.86 \\
& EC & 9.22 & 2.72 & 3.86 & 1.25 & 3.38 \\
& EO + EC & 10.01 & 8.06 & 8.56 & 11.58 & 6.24 \\
\hline \multirow{2}{*}{$2.0 \mathrm{~m}$} & EO & 1.45 & 5.81 & 5.01 & 10.66 & 3.27 \\
& EC & 8.90 & 2.01 & 3.52 & 1.16 & 3.03 \\
& EO + EC & 10.35 & 7.82 & 8.53 & 11.82 & 6.30 \\
\hline \multirow{2}{*}{ Area of reference mask } & 13.66 & 22.58 & 30.95 & 42.88 & 49.78 \\
\hline
\end{tabular}




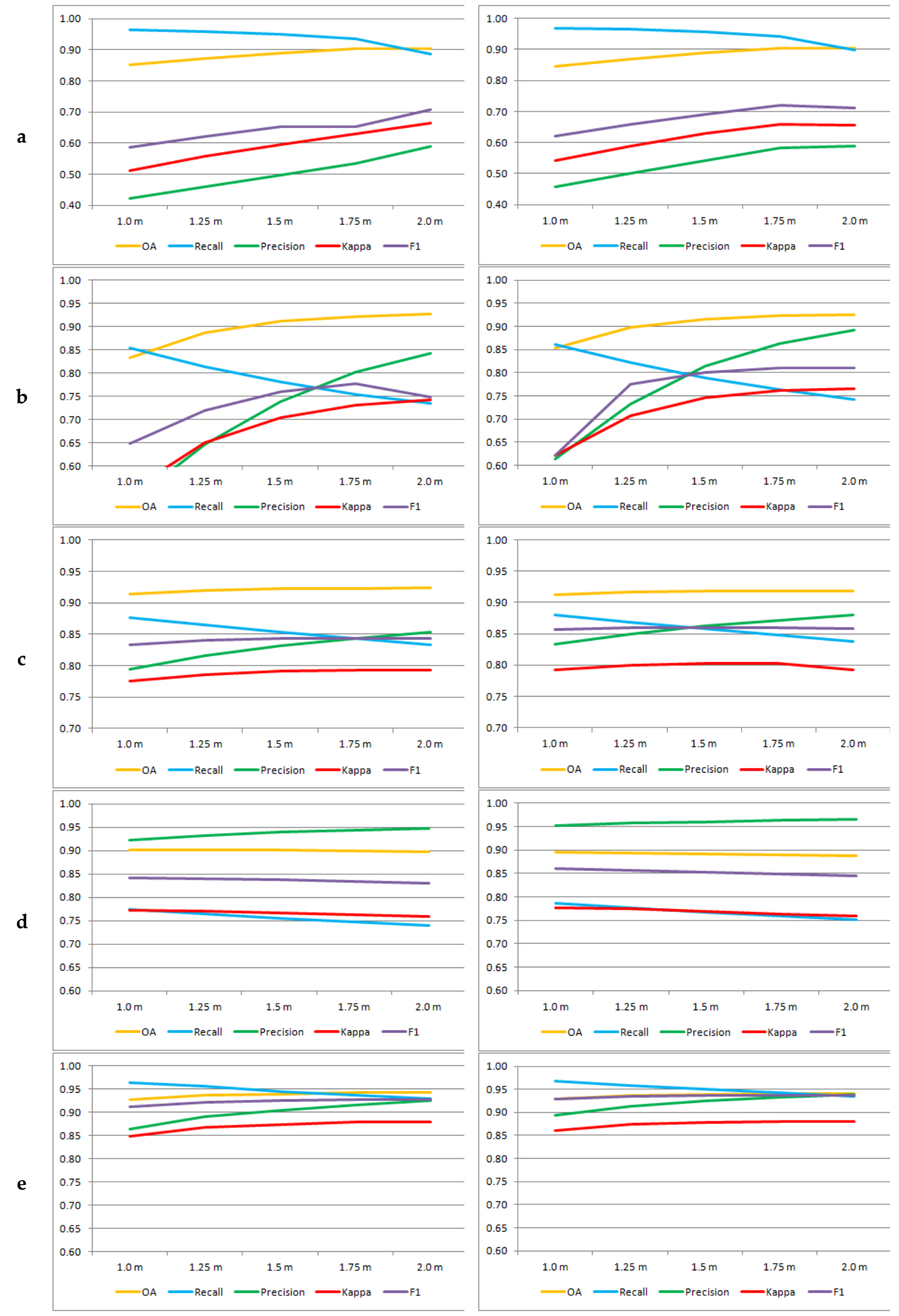

Figure 5. Comparison of accuracy coefficients for different threshold values (right-the whole analyzed area; left-excluding rocky outcrops and inliers), a. 1971, b. 1996, c. 2003, d. 2009, e. 2015. 
(a)

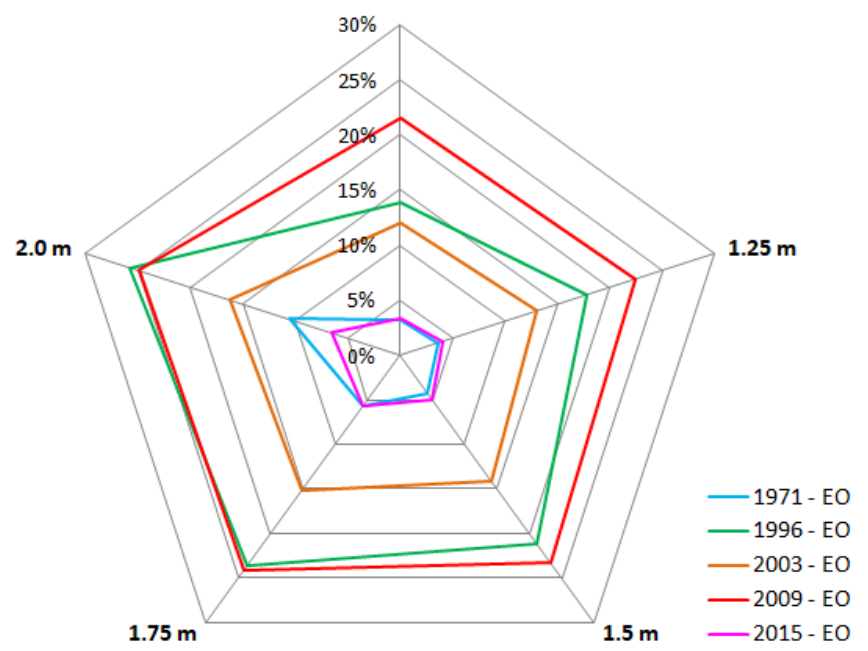

(b)

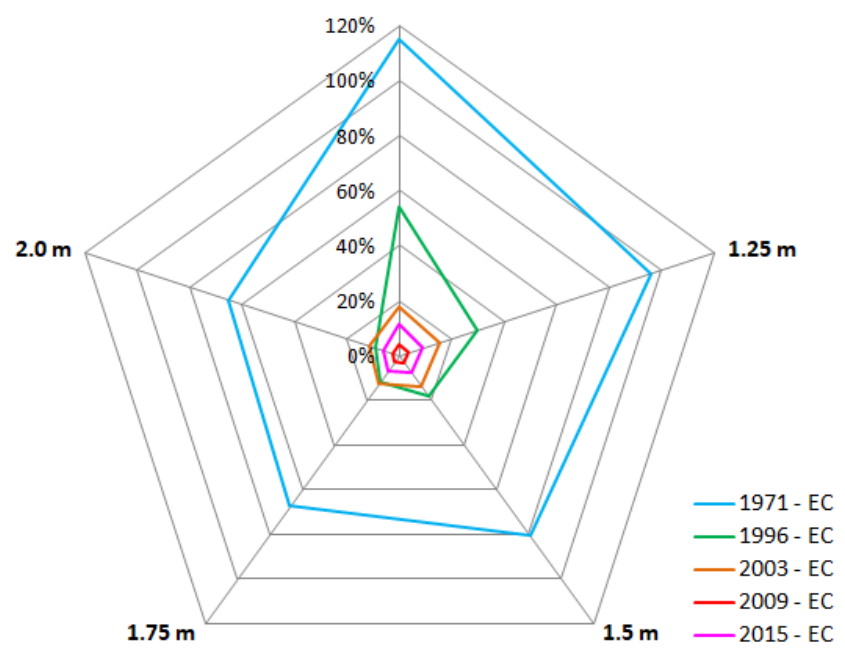

(c)

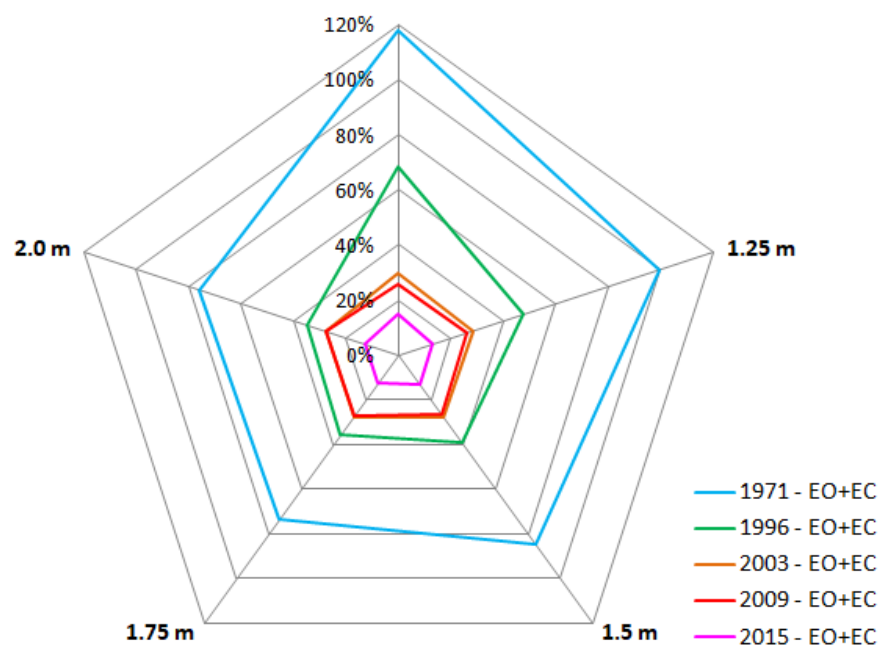

Figure 6. Comparison, in relation to the reference mask of trees and shrubs, (a) an area of omission (EO), (b) an area of commission (EC), and (c) sum of the area of omission and the area of commission $(\mathrm{EO}+\mathrm{EC})$ obtained for various cut-off height threshold values (excluding rocky outcrops and inliers).

\section{Discussion}

In this section the results are discussed, with reference to investigations reported in the literature on the use of dense image matching in DSM for defining the extent of trees and shrubs. 


\subsection{Analysis of Results Obtained Using Agisoft Photoscan and Trimble Inpho}

Based on the analysis of the results, it can be stated that generating point clouds based on archival images matching enables, in some cases, a detection of individual trees, and very often trees in forest stands with high canopy closure. Such detection is important because without it, trees and shrubs areas would be negligible in a DSM model. The results of the experiment aimed at the detection of single trees varied much, from a few percent to almost $70 \%$ for images taken in proper conditions and at appropriate times, while for trees in high canopy closure, the results of detection were better: from $40 \%$ to almost $100 \%$ of trees were detected from DSM. Such varied results are caused by different dates of photograph acquisition, the different image quality and algorithm of image matching. In relation to the obtained results, it can be stated that the photos with a scale of about 1:13,000 and digital images with a GSD equal to $25 \mathrm{~cm}$ acquired at the time of vegetation development (May-September) are the appropriate material for the analysis of vegetation succession.

When recommending parameters for the analysis of forest stands with high canopy closure, similar guidelines should be taken into account as those given when analyzing individual trees and their detection. However, a scale of less than 1:26,000 and a date beyond the development of vegetation do not necessarily exclude an analysis from use, as evidenced by the results obtained for the photographs from 1996 and 2012, respectively. The scale or GSD value consequently define the density of a generated point cloud. Denser point clouds provide a better chance of detection of a tree, as well as allowing for a more accurate, high measurement. Such a statement is also true for LiDAR-based DSM resolution [45]. Interpolation in DSM generation can also have an impact on model quality [28].

To generate clouds, it is much better to use professional photogrammetric software equipped with more powerful algorithms of dense image matching. In this research, Trimble Inpho with Semi Global Matching algorithm and elements of feature-based matching provided better results in the strategy of point cloud generation, which were more robust regarding problems with similarity and homogeneity of area. Due to the high resolution of point clouds generated in Agisoft Photoscan, areas with no data appeared. However, both approaches with Agisoft software provided slightly worse results than all the approaches with Trimble Inpho.

\subsection{The Influence of Cut-Off Height Thresholds on Determining the Extent of Trees and Shrubs}

As already mentioned, the difficulty in automating the procedure of generating the extent of trees and shrubs with the use of DIM technique, lies in the appropriate selection of the cut-off threshold, so as not to lose important information about the occurrence of earlier stages of succession. In various studies, the height cut-off threshold of $2 \mathrm{~m}[21,35-38]$ or $3 \mathrm{~m}[46,47]$ has been used, but these studies have examined forest areas and have not focused on the earlier stages of the succession process. In addition, the majority of scientific works have concentrated on the processing of newer aerial photographs acquired by digital cameras, not by analogue cameras. Therefore, it was decided that this study would analyze the impact of various height cut-off thresholds on the correctness of determining the extent of forested and bushy areas for each archival material.

As a result of the analysis, it was found that for each archival material, slightly different results were obtained. In the case of the oldest data—from 1971, at a scale of 1:18,000 - the highest accuracy $(\mathrm{F} 1$-score $=0.707$, and kappa $=0.663)$ was achieved at the threshold of $2 \mathrm{~m}$. However, $1.75 \mathrm{~m}$ is the threshold at which the total area of places mistakenly indicated as trees and shrubs, as well as omitted places, is the smallest (Figure 6). At this threshold, the F1-score is 0.653 and Cohen's kappa is 0.630 . Unfortunately, the total EO + EC area for this threshold is close to $68 \%$ of the reference mask, and at the threshold of $2 \mathrm{~m}$, it is $65 \%$ of the reference mask, with EC errors being the main factor. EO errors are ca. $5-10 \%$. Such large EC errors are mainly due to the radiometric quality of photos from this period. In some places, overestimation of the trees and shrubs area resulted from the presence of small rocks, as well as from the presence of cereals on the arable fields (photos registered in July).

The greatest impact on the accuracy of determining the extent of shrubs and trees based on photographs from 1996 was their scale $(1: 26,000)$. The highest F1 value was obtained for the $1.75 \mathrm{~m}$ 
threshold, and Cohen's kappa for the $2 \mathrm{~m}$ threshold. The total area size resulting from EO and EC errors was the smallest at the threshold of $2 \mathrm{~m}$, but the difference between the area obtained with this value and the value of $1.75 \mathrm{~m}$ was small (35\% vs. $36 \%$ in relation to the reference mask). The EC error for the threshold of $1.5 \mathrm{~m}$ was less than $20 \%$ of the reference mask, and the EO error was within 20-25\% (Figure 6). In Figure 7, the effect of decreasing the threshold value on the increase of EC errors can be seen, especially in the area with rocky outcrops and inliers. In the case of these photographs, it should also be mentioned that due to the smaller scale, their photointerpretation (preparation of reference data) was difficult, so some of the EC errors might have resulted from the incompleteness of the reference data.

The next photos-from 2003, 2009 and 2015-were data of similar parameters of scale/GSD. Using the photographs from 2003, high values of F1 for the $1.25 \mathrm{~m}$ cut-off threshold $(\mathrm{F} 1=0.840)$ were obtained. For higher height cut-off values, the F1-score increased slightly (up to 0.844 for the $1.75 \mathrm{~m}$ and $2 \mathrm{~m}$ thresholds). The same trends were observed for Cohen's kappa coefficient values. The total area EO and EC for the threshold values from $1.25 \mathrm{~m}$ was $28 \%$ of the reference area (Figure 6). EO and EC errors were at a similar level (several percent of the reference mask area), and none of them had a dominant influence on the accuracy assessment. This was due both to the scale of the photographs $(1: 14,000)$ and their radiometric quality, as well as the date of obtaining the photos (May). During this period, cereals in the fields, as well as natural herbs, had not yet grown high. Similar observations were made for data from 2015. The only difference was that the error values of EO and EC were two times lower (5-6\% of the surface of the reference mask). The highest F1 value for the $1.75 \mathrm{~m}$ cut-off threshold $(\mathrm{F} 1=0.926)$ was obtained for 2015. Nevertheless, for the threshold of $1.5 \mathrm{~m}, \mathrm{~F} 1$ was only 0.002 lower, and for $1 \mathrm{~m}$, it was lower by 0.005. Analyzing other accuracy parameters, as well as visually assessing the obtained extent of trees and shrubs, one can assume that the $1.5 \mathrm{~m}$ threshold - in the case of 2015 data-allowed for obtaining the best results. Errors from revaluation resulted mainly from the late date of acquiring these images (August), and consequently, the fact that vegetation on arable fields and herbaceous plants had already grown high, so at the height threshold of 1 to $1.5 \mathrm{~m}$, some patches of this vegetation could have been detected as shrubbery areas.

The data from 2009 were acquired in Spring, when deciduous trees and shrubs were not fully leafed. As a result, the highest value of F1-score (0.842) was obtained for the $1 \mathrm{~m}$ cut-off height threshold. Cohen's kappa coefficient for this threshold was also the largest. This was the only period when the accuracy of determining the extent of trees and shrubs clearly decreased with the increase of the threshold values. In this period, larger EO errors (around 20\% of the reference mask) than EC errors were observed. This is obviously due to the date of acquiring photos-herbaceous plants had not yet grown, so did not affect the overestimation of results, while the crowns of trees and shrubs had poor foliage.

Figure 6 clearly shows the influence of the quality of archival photos on the obtained results. The worst results (the biggest EO + EC errors) were obtained for 1971 (B/W, 1:18,000, low radiometric quality, with scratches on the film), and then for data from 1996 (RGB, 1:26,000). The best results were achieved for photos from 2015 obtained with a digital camera (RGB, GSD = $25 \mathrm{~cm}$ ). Slightly lower accuracy was achieved with photographs from 2003 (B/W, 1:13,000) and 2009 (RGB, 1:14,000). The ratio between the EC and EO areas was different for both of these terms, which resulted from the phenological period in which the images were acquired.

Figure 7 shows, for a fragment of the analyzed area, the impact of the cut-off threshold values on determining the extent of trees and shrubs. A worse detection of low and relatively small trees and shrubs can be observed, which affects the error of omission (EO). For each of the dates, errors are evident that result from the inclusion of rock outliers and inliers in the designated extents. When CIR photos are examined, spectral information can be used to remove non-vegetative objects. However, one must bear in mind the fact that some of the rocks could be covered with vegetation and it will not always be possible to eliminate them. In such a situation, one should use the current ALS data from the leafless period (early spring), after a detailed (manually supported) point cloud classification, which would make it possible to obtain an accurate DTM. 

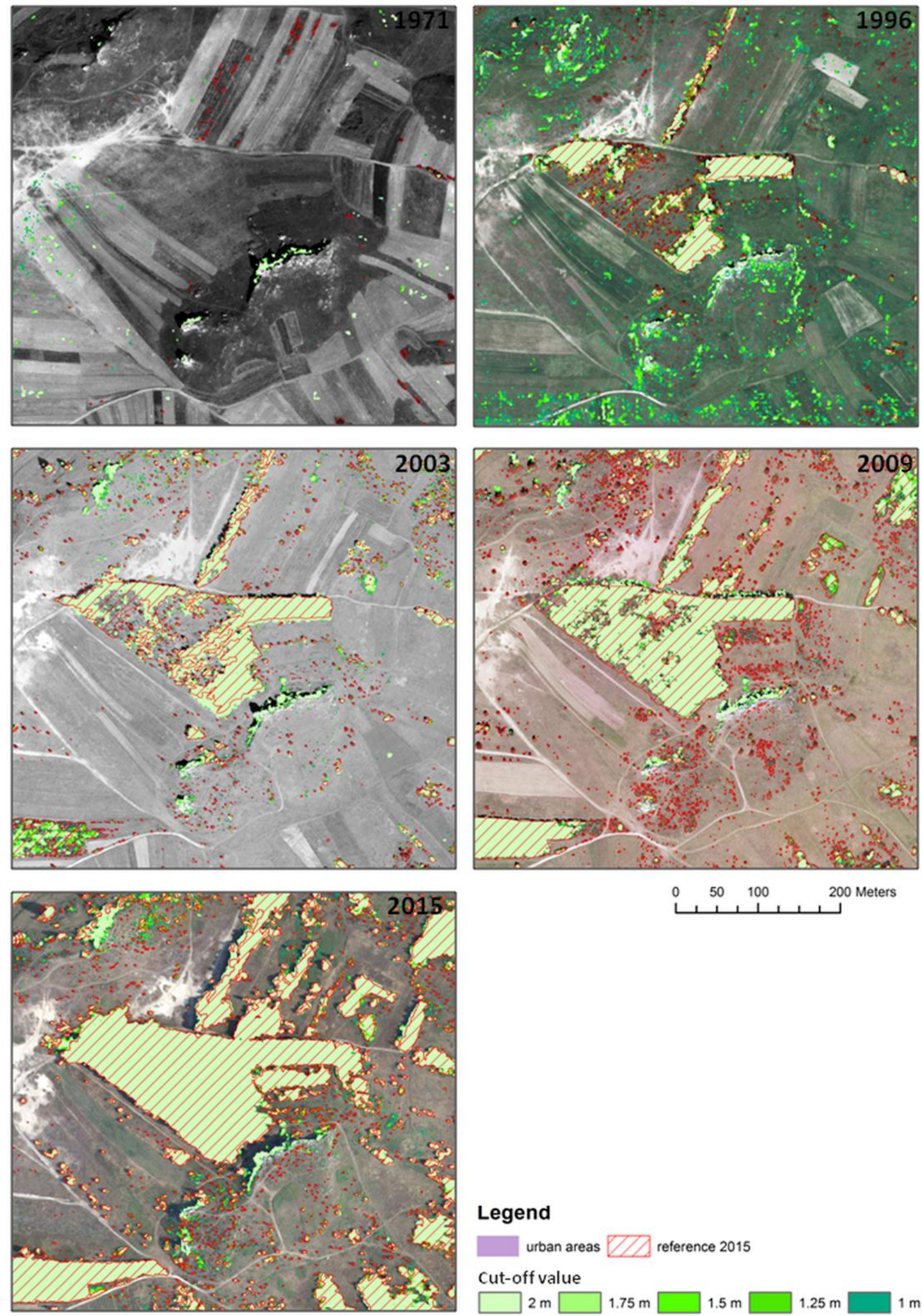

\section{Legend}

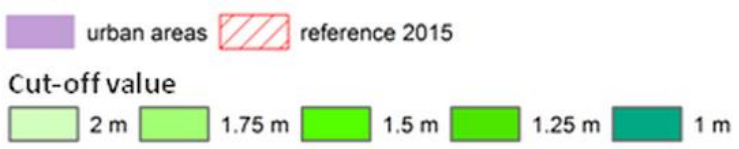

Figure 7. Comparison of extent of trees and shrubs for each dataset, obtained using different cut-off height threshold values (part of the study area). 


\subsection{Comparison of the Results of the Best Variants with Reference Data}

As the final spatial extents of trees and shrubs for each period were selected, those extents were characterized by high accuracy (F1-score) and a small total area EO + EC. The resulting extents of trees and shrubs obtained for each dataset using DIM techniques for part of the study area is shown in Figure 8. The comparison of the correctly indicated area with the area resulting from errors of omission (EO) and error of commission (EC), for each of the analyzed periods, is presented in the graph (Figure 9). The graph shows results in the form of absolute (Figure 9a) and relative values (Figure $9 b$ ). The increase in the area covered by succession vegetation is clearly visible. In addition, the highest error of commission is observed for data from 1971-as much as $42 \%$. In subsequent periods, the surface rate resulting from excess errors (EC) ranges from $5 \%$ to $14 \%$. The differences in this error rate resulted from the scale of photos (small scale for 1971 and 1996) and the quality and dates of acquiring photographs (1971). The impact of the period of time is also visible in the erroneous underestimation of the area occupied by trees and shrubs, and this can be seen particularly for the data from 2009 , where the underestimation error is $26 \%$ (data was obtained in early spring).

Analyzing Figure 9, it can be concluded that the error of determining the wooded and shrubbed areas using DIM algorithms can be estimated at $15-30 \%$ depending on the date and technical parameters of archival photos. A lower rate of errors is observed in the case of photographs acquired by digital cameras, which can be seen when comparing the results obtained for 2015 images (registered using a digital camera) and 2003 photos (registered using an analogue camera) (Figure 8).

\section{Conclusions}

In the presented research, an assessment of the possibility of using DIM algorithms to delimitate the extents of forested and shrubbed areas, based on archival aerial photographs with different technical parameters, was carried out. The research was carried out using this technology for monitoring the dynamics of the process of succession of trees and shrubs. In order to determine the effectiveness of DIM techniques, the algorithms implemented in Agisoft Photoscan and Trimble Inpho software were tested. Finally, the effect of nDSM height threshold on the correctness of determining the extent of trees and shrubs was investigated.

By analyzing the contemporary quality of aerial photographs captured with a digital camera, it is possible to detect an object using nDSM derived from DIM data, with a very high probability of reaching nearly $100 \%$. The DIM algorithm, including feature-based approach eliminating errors related to homogeneity and similarity of the area, also allows for determining the correct height of trees, with a very high accuracy of only a few percent difference. These conclusions apply both to trees growing singly, and in stands with high canopy closure. The situation is slightly different as regards archival photos. The quality of detection and determining the height of trees is affected by the quality of photos and their parameters, which in the past were less favorable, as well as the period of obtaining data- unfavorable in a leaf-off situation and favorable for leaf-on. These circumstances significantly reduce the ability to detect individual trees. Detection of trees in high canopy closure was not influenced by these factors. Algorithms of image matching also allowed for a reliable determination of trees through all the years of image acquisition. In the case of detection of both trees growing singly and in high canopy closure, their heights showed an increasing trend, analyzing the subsequent acquisition dates. A larger dispersion of values was recorded for trees growing singly.

In the conducted research, a better dense image matching performance was observed, with parameters providing higher point cloud density and low smoothing of the model. Considering algorithms compared in the software used, dense image matching from Trimble Inpho and Agisoft Photoscan worked comparably for modern images when parameters were properly set. When archived data were used, better results were achieved for Trimble Inpho image matching algorithms. Worse image quality, lower image resolution and unfavorable period of data collection required an image matching strategy that involved steps based on both feature- and area-based approaches. 

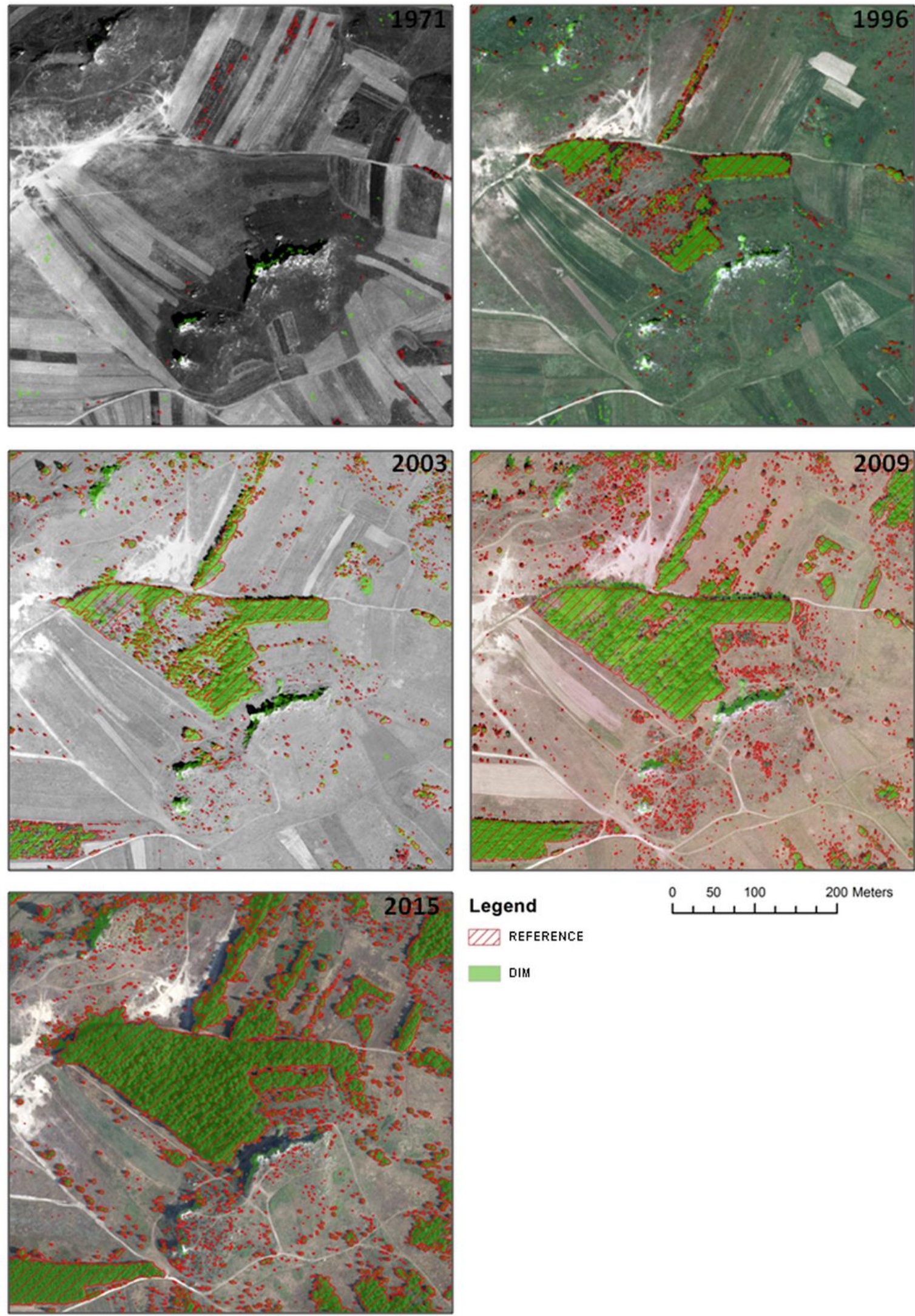

\section{Legend \\ DIA REFERENCE}

$0 \quad 50 \quad 100$ 200 Meters

DIM

Figure 8. Comparison of the resulting extents of trees and shrubs obtained for each dataset using DSM from DIM techniques with reference data (part of the study area). 


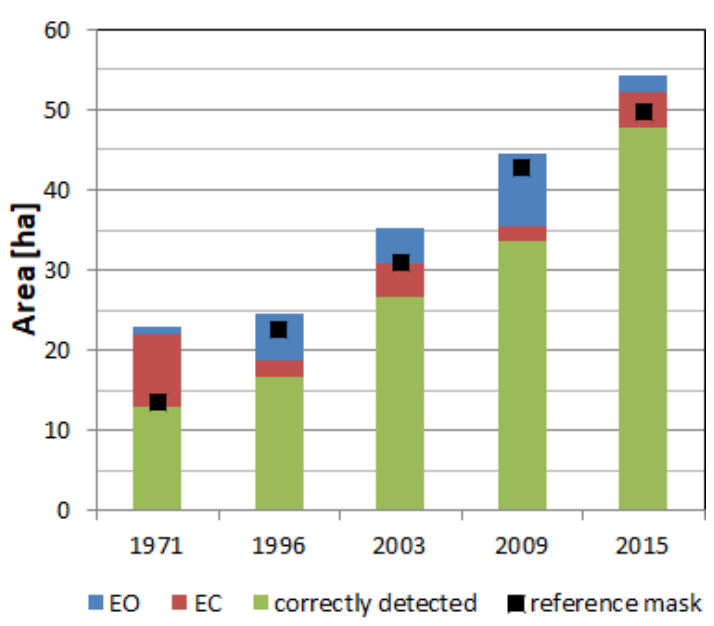

(a)

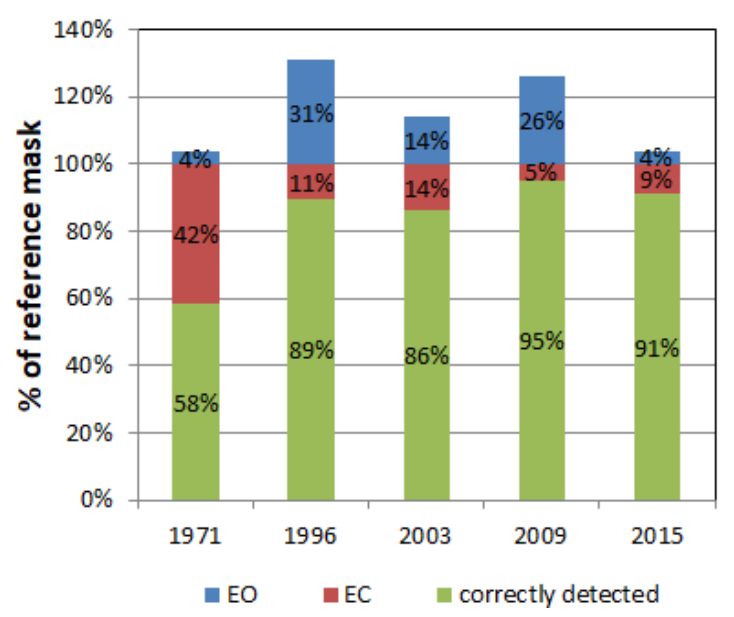

(b)

Figure 9. Area of correctly detected trees and shrubs (in green), area of omissions (EO) and area of commission (EC) for each archival dataset: (a) absolute values, (b) values calculated in relation to the reference mask area.

As a result of the analysis of the use of the generated elevation model, it was found that for archival photographs of good radiometric quality and a scale of not less than 1:13,000 or maximum GSD of $25 \mathrm{~cm}$, the optimal cut-off threshold for determining the succession extent of trees and shrubs was 1.25-1.75 m. With this threshold, the error of determining the extent of trees and shrubs can be estimated at 10 to $30 \%$, depending on the technical parameters of the images and the date of their acquisition. An important element in defining the cut-off threshold is the phenological development of vegetation during aerial images collection.

For spring images, the cut-off may be lower (even $1 \mathrm{~m}$ ), because herbaceous vegetation is not yet developed and is of relatively small size. The spring term is particularly recommended for determining the range of succession of coniferous trees and shrubs. When choosing the threshold value, both the acquisition date of archival photos and the specificity of land cover of the analyzed area should be taken into account, and in particular, the possibility of occurrence of high herbaceous plants, which may hinder the process of obtaining the correct extent of trees and shrubs.

The results of the present study have served as recommendations in the development of methodology for analyzing the dynamics of trees and shrubs succession process using archival aerial photographs, implemented by the project leader, MGGP Aero company.

Author Contributions: The aim of the study and the methodology of research: K.O.-S. and K.B., DIM techniques application: Ł.J. and K.B.; reference data preparation: A.P. and K.O.-S.; analysis of DIM results: Ł.J., K.B. and K.O.-S.; results analysis, preparation of tables and charts, synthesis of the study data: K.O-S., J.E. and K.B.; writing-original draft preparation: K.O.-S., ŁJ. and K.B.; writing-review and editing: K.O.-S. and K.B.; visualizations preparation: K.O.-S., K.B. and J.Ł.; WP5 leading and supervision: K.O.-S.

Funding: The study co-financed by the Polish National Centre for Research and Development (NCBiR), project No. DZP/BIOSTRATEG-II/390/2015: The innovative approach supporting monitoring of non-forest Natura 2000 habitats, using remote sensing methods (HabitARS). The Consortium Leader is MGGP Aero. The project partners include: University of Lodz, University of Warsaw, Warsaw University of Life Sciences, Institute of Technology and Life Sciences, University of Silesia in Katowice, Warsaw University of Technology. The leader of WP5 (Methodology for the identification of the trees and shrubs succession process in the area of non-forest Natura 2000 habitats) is Warsaw University of Technology. The article processing charge was financed from the statutory subsidy of the Faculty of Geodesy and Cartography.

Conflicts of Interest: The authors declare no conflict of interest. The funders had no role in the design of the study; in the collection, analyses, or interpretation of data; in the writing of the manuscript, or in the decision to publish the results. 


\section{Appendix A}

Table A1. Single trees detection rate for all datasets.

\begin{tabular}{|c|c|c|c|c|c|c|c|c|c|}
\hline \multirow{2}{*}{ Date } & \multirow{2}{*}{ Statistics } & \multicolumn{6}{|c|}{ Trimble Inpho } & \multicolumn{2}{|c|}{ Agisoft Photoscan } \\
\hline & & v1 & v2 & v3 & $\mathrm{v} 4$ & v5 & v6 & High & Medium \\
\hline 11 August 1971 & $\%$ detected & 36 & 35 & 41 & 39 & 38 & 36 & 30 & 30 \\
\hline leaf-on & average height in $\%$ of ALS & 71 & 70 & 70 & 69 & 65 & 66 & 53 & 63 \\
\hline 31 May 1982 & $\%$ detected & 14 & 15 & 18 & 15 & 11 & 9 & 16 & 9 \\
\hline leaf-on & average height in $\%$ of ALS & 62 & 64 & 58 & 58 & 61 & 55 & 51 & 46 \\
\hline 30 May 1996 & $\%$ detected & 26 & 28 & 28 & 28 & 23 & 22 & 8 & 3 \\
\hline leaf-on & average height in $\%$ of ALS & 79 & 76 & 76 & 76 & 83 & 82 & 87 & 79 \\
\hline 24 May 2003 & $\%$ detected & 66 & 64 & 66 & 64 & 69 & 59 & 30 & 41 \\
\hline leaf-on & average height in $\%$ of ALS & 87 & 87 & 87 & 86 & 84 & 85 & 80 & 70 \\
\hline 26, 29 April 2009 & $\%$ detected & 38 & 38 & 39 & 38 & 39 & 36 & 30 & 22 \\
\hline leaf-on & average height in $\%$ of ALS & 84 & 85 & 85 & 86 & 84 & 82 & 77 & 71 \\
\hline 25 March 2012 & $\%$ detected & 20 & 20 & 22 & 21 & 20 & 19 & 20 & 3 \\
\hline leaf-off & average height in $\%$ of ALS & 77 & 77 & 79 & 78 & 76 & 70 & 71 & 58 \\
\hline 8 August 2015 & $\%$ detected & 93 & 93 & 99 & 96 & 95 & 94 & 89 & 69 \\
\hline leaf-on & average height in $\%$ of ALS & 94 & 94 & 95 & 94 & 94 & 91 & 89 & 73 \\
\hline
\end{tabular}

Table A2. Trees in high canopy closure detection rate for all datasets.

\begin{tabular}{|c|c|c|c|c|c|c|c|c|c|}
\hline \multirow{2}{*}{ Date } & \multirow{2}{*}{ Statistics } & \multicolumn{6}{|c|}{ Trimble Inpho } & \multicolumn{2}{|c|}{ Agisoft Photoscan } \\
\hline & & v1 & v2 & v3 & $\mathrm{v} 4$ & v5 & v6 & High & Medium \\
\hline 11 August 1971 & $\%$ detected & 64 & 64 & 82 & 65 & 63 & 62 & 56 & 56 \\
\hline leaf-on & average height in $\%$ of ALS & 49 & 49 & 55 & 49 & 48 & 48 & 48 & 48 \\
\hline 31 May 1982 & $\%$ detected & 62 & 64 & 58 & 57 & 61 & 55 & 51 & 46 \\
\hline leaf-on & average height in $\%$ of ALS & 47 & 47 & 48 & 48 & 48 & 48 & 48 & 45 \\
\hline 30 May 1996 & $\%$ detected & 86 & 84 & 85 & 84 & 82 & 86 & 82 & 82 \\
\hline leaf-on & average height in $\%$ of ALS & 69 & 70 & 70 & 70 & 70 & 69 & 68 & 66 \\
\hline 24 May 2003 & $\%$ detected & 88 & 88 & 88 & 88 & 89 & 89 & 37 & 94 \\
\hline leaf-on & average height in $\%$ of ALS & 77 & 77 & 80 & 77 & 76 & 77 & 73 & 74 \\
\hline 26, 29 April 2009 & $\%$ detected & 95 & 95 & 92 & 94 & 93 & 95 & 38 & 85 \\
\hline leaf-on & average height in $\%$ of ALS & 85 & 86 & 87 & 86 & 85 & 85 & 77 & 82 \\
\hline 25 March 2012 & $\%$ detected & 77 & 76 & 77 & 77 & 76 & 76 & 75 & 78 \\
\hline leaf-off & average height in $\%$ of ALS & 87 & 88 & 90 & 89 & 88 & 86 & 87 & 84 \\
\hline 8 August 2015 & $\%$ detected & 100 & 100 & 100 & 100 & 100 & 100 & 100 & 100 \\
\hline leaf-on & average height in $\%$ of ALS & 98 & 98 & 100 & 99 & 98 & 97 & 97 & 95 \\
\hline
\end{tabular}




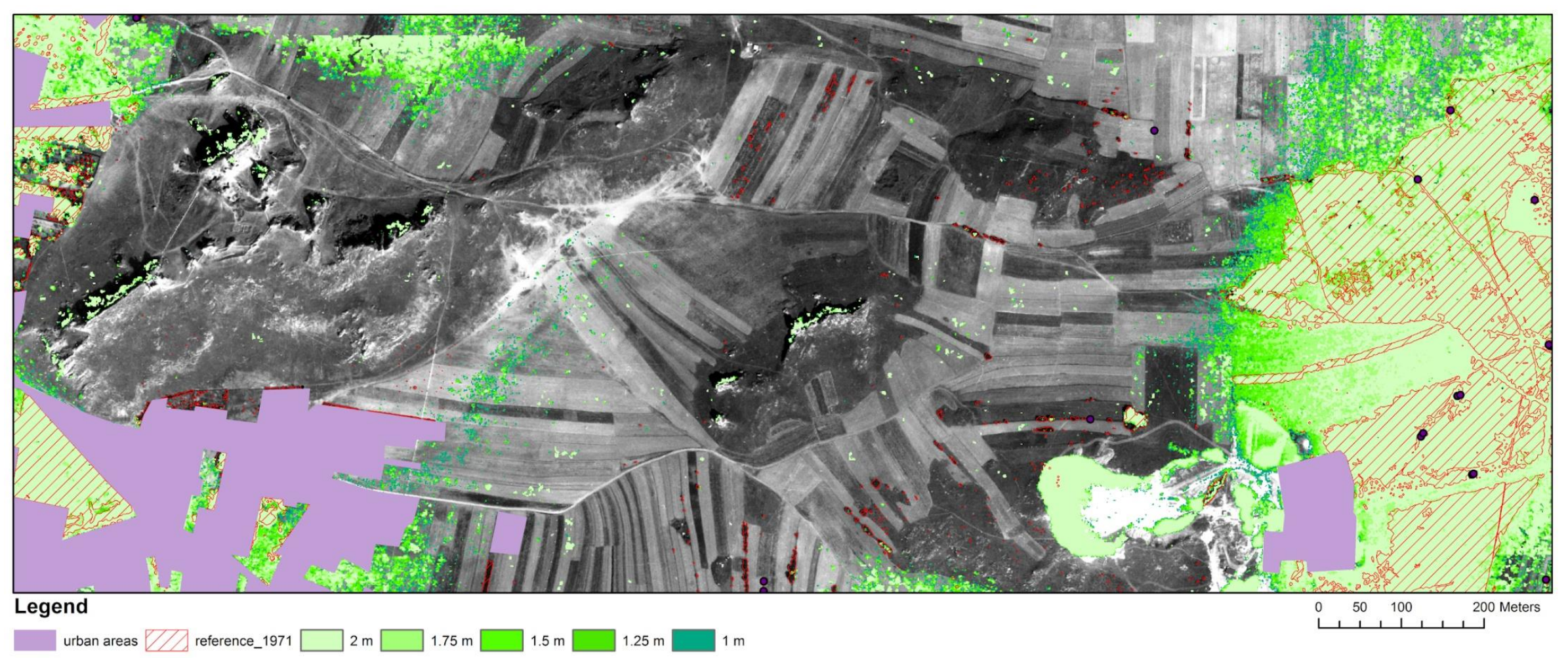

Figure A1. Comparison of extent of trees and shrubs obtained for different threshold values with reference data for 1971. 


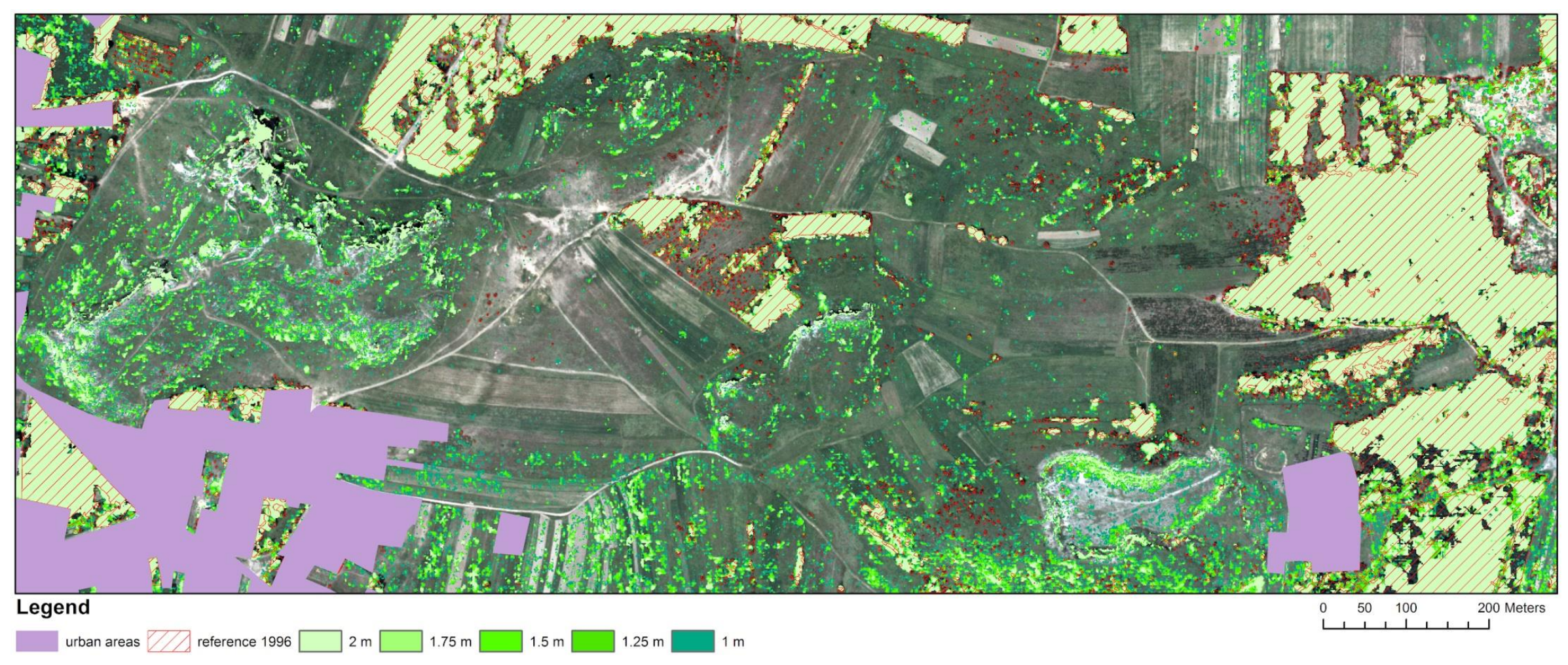

Figure A2. Comparison of extent of trees and shrubs obtained for different threshold values with reference data for 1996. 


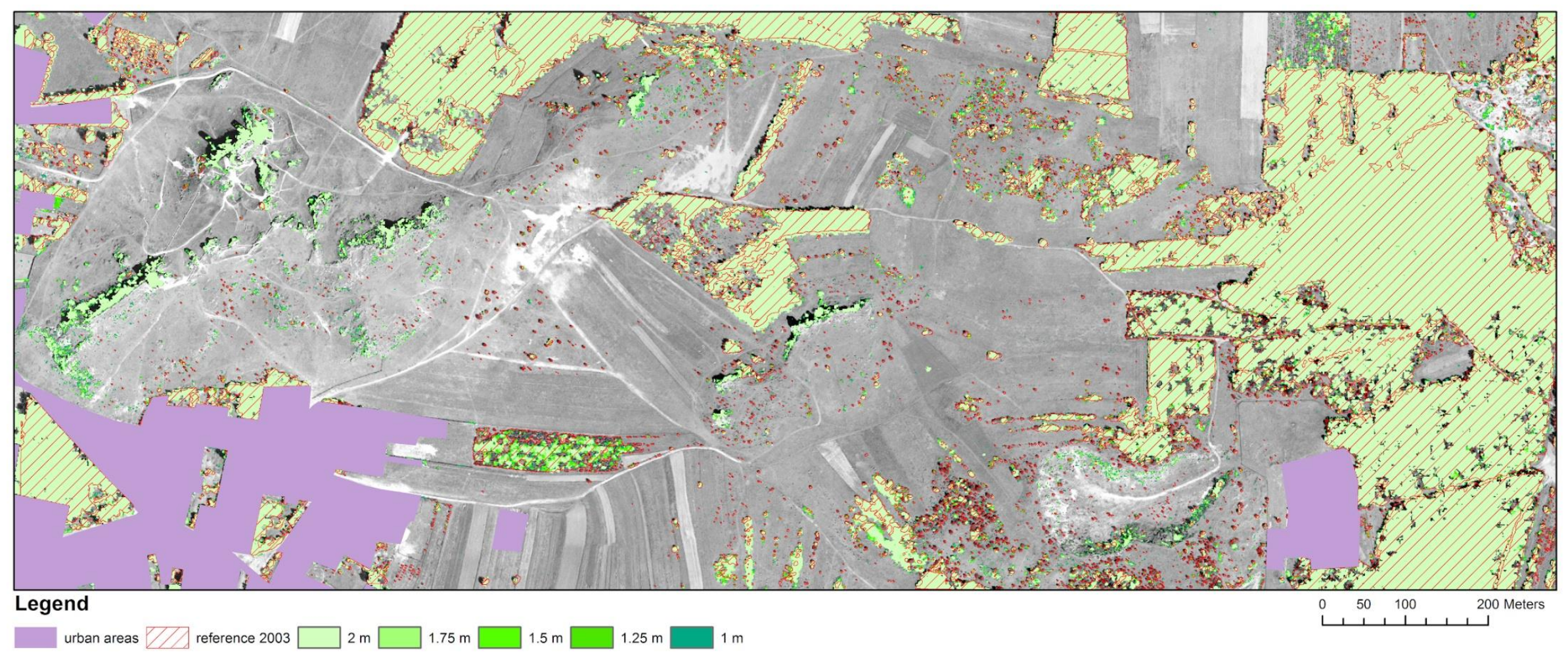

Figure A3. Comparison of extent of trees and shrubs obtained for different threshold values with reference data for 2003. 


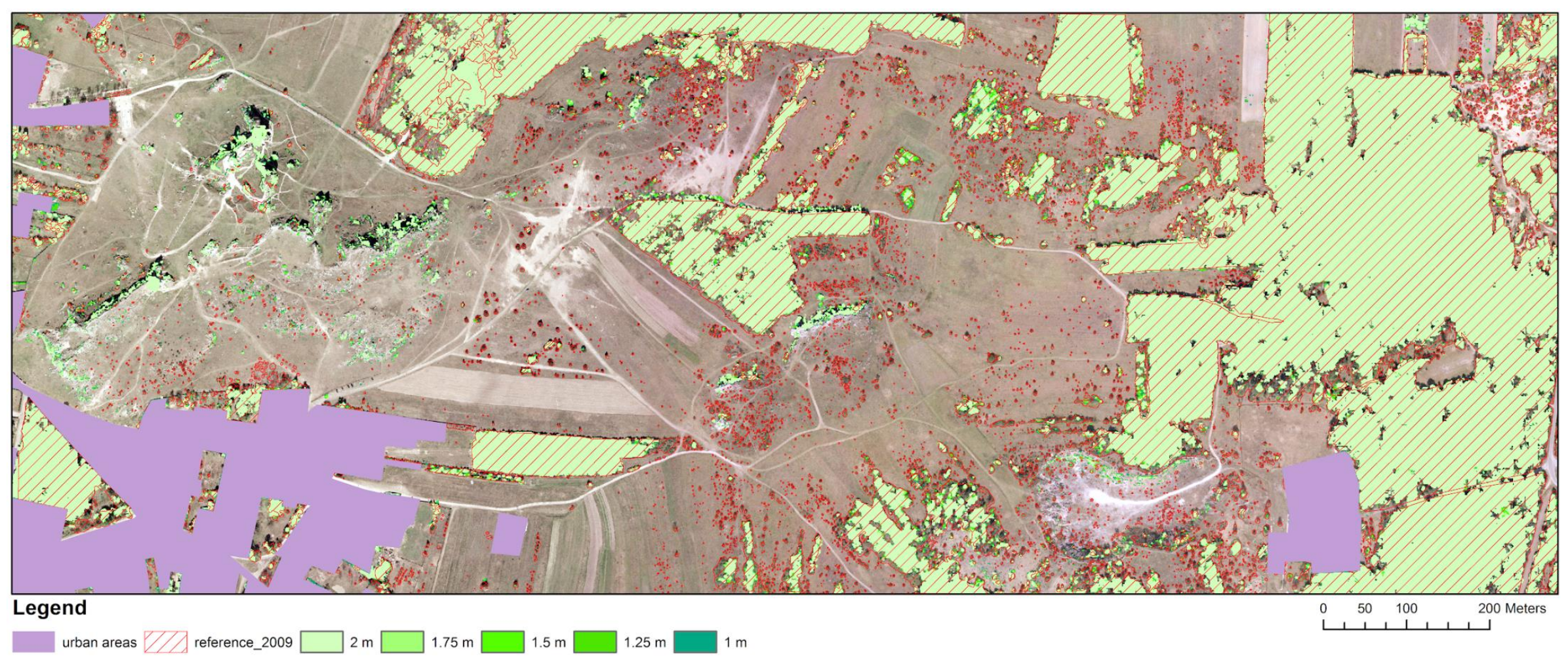

Figure A4. Comparison of extent of trees and shrubs obtained for different threshold values with reference data for 2009. 


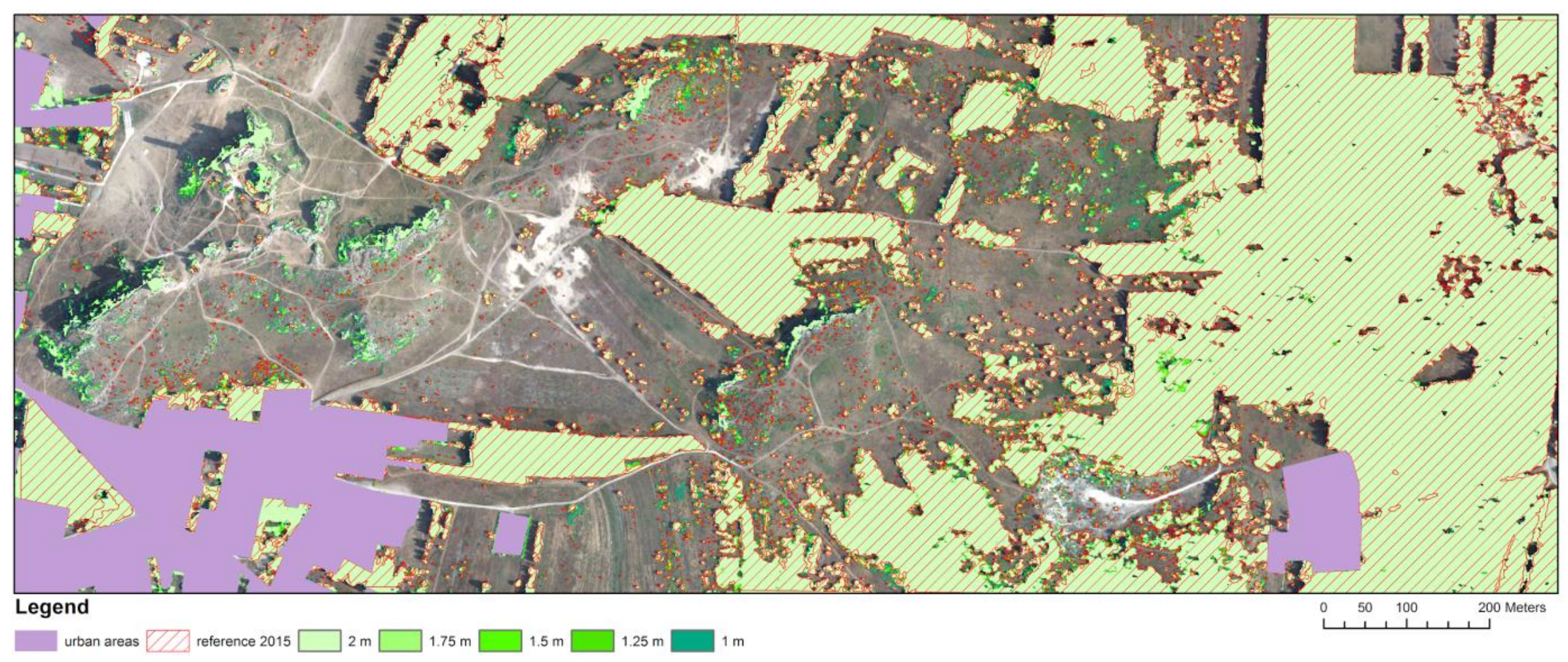

Figure A5. Comparison of extent of trees and shrubs obtained for different threshold values with reference data for 2015. 


\section{References}

1. EEA. Available online: https://www.eea.europa.eu/data-and-maps/data/article-17-database-habitatsdirective-92-43-eec (accessed on 1 July 2019).

2. European Commission. The Habitat Directive. Available online: http://ec.europa.eu/environment/nature/ legislation/habitatsdirective/index_en.htm (accessed on 1 July 2019).

3. Mróz, W. Monitoring Siedlisk Przyrodniczych. Przewodnik Metodyczny [Natura 2000 Habitat Monitoring]; Part I.; Biblioteka Monitoringu Środowiska: Warszawa, Poland, 2010.

4. Falkowski, M.J.; Evans, J.S.; Martinuzzi, S.; Gessler, P.E.; Hudak, A.T. Characterizing forest succession with LIDAR data: An evaluation for the Inland Northwest, USA. Remote Sens. Environ. 2009, 113, 946-956. [CrossRef]

5. Kolecka, N.; Kozak, J.; Kaim, D.; Dobosz, D.; Ginzler, C.; Psomas, A. Mapping secondary forest succession on abandoned agricultural land with LiDAR point clouds and terrestrial photography. Remote Sens. 2015, 7, 8300-8322. [CrossRef]

6. Próchnicki, P. The implementation of gis and remote sensing to analysis of shrub succession in the Narew National Park. Rocz. Geomatyki 2006, 2, 127-134.

7. Maryniak, D.; Drzewiecki, W. Land cover changes in Błędowska Desert area between 1926 and 2005. Arch. Fotogram. Kartogr. i Teledetekcji 2010, 21, 245-256.

8. Rahmonov, O.; Oleś, W. Vegetation succession over an area of a medieval ecological disaster. The case of the Błędów Desert, Poland. Erkunde 2010, 64, 241-255. [CrossRef]

9. Bryś, H.; Gołuch, P. Pustynia Błędowska dawniej i dziś-interpretacja wieloczasowych zdjęć lotniczych i obrazów satelitarnych. Acta Sci. Pol. Geod. et Descr. Terrarum 2011, 10, 5-15.

10. Oikonomakis, N. Land cover changes and forest succession trends in a site of Natura 2000 network (Elatia forest), in northern Greece. For. Ecol. Manag. 2012, 285, 153-163. [CrossRef]

11. Kolecka, N.; Dobosz, M.; Ostafin, K. Forest cover change and secondary forest succession since 1977 in Budzów Commune, the Polish Carpathians. Pr. Geogr. Inst. Geogr. i Gospod. Przestrz. Uniw. Jagiellońskiego 2016, 146, 51-65.

12. Holopainen, M.; Jauhiainen, S. Detection of peatland vegetation types using digitized aerial photographs. Can. J. Remote Sens. 1999, 25, 475-485. [CrossRef]

13. Miller, M.E. Use of historic aerial photography to study vegetation change in the Negrito Creek watershed, southwestern New Mexico. Southwest. Nat. 1999, 44, 121-137.

14. Pitt, D.; Runesson, U.; Bell, F.W. Application of large- and medium-scale aerial photographs to forest vegetation management: A case study. For. Chron. 2000, 76, 903-913. [CrossRef]

15. Ligocki, M. Zastosowanie zdjęć lotniczych do badania sukcesji wtórnej na polanach śródleśnych. Teledetekcja Środowiska 2001, 32, 143-151.

16. Wężyk, P.; Sztremer, M. Using digital photogrammetry, GPS and GIS in vegetation mapping of the Babia Gora National Park. Rocz. Geomatyki 2005, 3, 173-180.

17. Jauhiainen, S.; Holopainen, M.; Rasinmäki, A. Monitoring peatland vegetation by means of digitized aerial photographs. Scand. J. For. Res. 2007, 22, 168-177. [CrossRef]

18. Hościło, A. Sukcesja roślinności zaroślowej na obszarze basenu środkowego Biebrzańskiego Parku Narodowego. Pr. Inst. Geod. i Kartogr. 2004, 4, 117-124.

19. Szostak, M.; Wężyk, P.; Hawryło, P.; Puchała, M. Monitoring the secondary forest succession and land cover/use changes of the Błędów Desert (Poland) Using Geospatial Analyses. Quaest. Geogr. 2016, 35, 5-13. [CrossRef]

20. Hirschmüller, H. Stereo processing by semi-global matching and mutual information. IEEE Trans. Pattern Anal. Mach. Intell. 2008, 30, 328-341. [CrossRef]

21. Stepper, C.; Straub, C.; Pretzsch, H. Using semi-global matching point clouds to estimate growing stock at the plot and stand levels: Application for a broadleaf-dominated forest in central Europe. Can. J. For. Res. 2015, 45, 111-123. [CrossRef]

22. Ali-Sisto, D.; Packalen, P. Forest change detection by using point clouds from dense image matching together with a LiDAR-Derived terrain model. IEEE J. Sel. Top. Appl. Earth Obs. Remote Sens. 2017, 10, 1197-1206. [CrossRef] 
23. Goodbody, T.R.H.; Coops, N.C.; Hermosilla, T.; Tompalski, P.; McCartney, G.; MacLean, D.A. Digital aerial photogrammetry for assessing cumulative spruce budworm defoliation and enhancing forest inventories at a landscape-level. ISPRS J. Photogramm. Remote Sens. 2018, 142, 1-11. [CrossRef]

24. White, J.C.; Tompalski, P.; Coops, N.C.; Wulder, M.A. Comparison of airborne laser scanning and digital stereo imagery for characterizing forest canopy gaps in coastal temperate rainforests. Remote Sens. Environ. 2018, 208, 1-14. [CrossRef]

25. Hirschmüller, H. Accurate and efficient stereo processing by semi-global matching and mutual information. In Proceedings of the 2005 IEEE Computer Society Conference on Computer Vision and Pattern Recognition (CVPR), San Diego, CA, USA, 20-26 June 2005; Volume 2, pp. 807-814. [CrossRef]

26. Gehrke, S.; Morin, K.; Downey, M.; Boehrer, N.; Fuchs, T. Semi-global matching: An alternative to LIDAR for DSM Generation? In Proceedings of the 2010 Canadian Geomatics Conference and Symposium of Commission I: ISPRS Convergence in Geomatics-Shaping Canada's Competitive Landscape, Calgary, AB, Canada, 15-18 June 2010.

27. Remondino, F.; Spera, M.G.; Nocerino, E.; Menna, F.; Nex, F.; Gonizzi-Barsanti, S. Dense image matching: Comparisons and analyses. In Proceedings of the IEEE Digital Heritage International Congress (Digital Heritage) 2013, Marseille, France, 28 October-1 November 2013; Volume 1, pp. 47-54.

28. Dominik, W. Exploiting the redundancy of multiple overlapping aerial images for dense image matching based digital surface model generation. Remote Sens. 2017, 9, 490. [CrossRef]

29. Haala, N. Dense Image Matching Final Report; EuroSDR Publication Series; Official Publication, Buchdruckerei Ernst Becvar: Vienna, Austria, 2014; pp. 115-145.

30. Osińska-Skotak, K.; Jełowicki, Ł.; Bakuła, K.; Michalska-Hejduk, D.; Wylazłowska, J.; Kopeć, D. Analysis of using dense image matching techniques to study the process of secondary succession in non-forest Natura 2000 habitats. Remote Sens. 2019, 11, 893. [CrossRef]

31. Véga, C.; St-Onge, B. Mapping site index and age by linking a time series of canopy height models with growth curves. For. Ecol. Manag. 2009, 257, 951-959. [CrossRef]

32. Haala, N. Comeback of Digital Image Matching. Photogrammetric Week 2009; Wichmann: Heidelberg, Germany, 2009; pp. 289-301.

33. Haala, N.; Rothermel, M. Dense multi-stereo matching for high quality digital elevation models. Photogramm. Fernerkun. 2012, 4, 331-343. [CrossRef]

34. St-Onge, B.; Achaichia, N. Measuring forest canopy height using a combination of LIDAR and aerial photography data. Int. Arch. Photogramm. Remote Sens. Spat. Inf. Sci. 2001, 34, 22-24.

35. Nilsson, M. Estimation of tree heights and stand volume using an airborne LiDAR system. Remote Sens. Environ. 1996, 56, 17. [CrossRef]

36. Næsset, E. Predicting forest stand characteristics with airborne scanning laser using a practical two-stage procedure and field data. Remote Sens. Environ. 2002, 80, 88-99. [CrossRef]

37. Nurminen, K.; Karjalainen, M.; Yu, X.; Hyyppa, J.; Honkavaara, E. Preformance of dense digital surface models based on image matching in the estimation of plot-level forest variables. ISPRS J. Photogramm. Remote Sens. 2013, 83, 104-115. [CrossRef]

38. Vastaranta, M.; Wulder, M.A.; White, J.C.; Pekkarinen, A.; Tuominen, S.; Ginzler, C.; Kankare, V.; Holopainen, M.; Hyyppa, J.; Hyyppa, H. Airborne laser scanning and digital stereo imagery measures of forest structure: Comparative results and implications to forest mapping and inventory update. Can. J. Remote Sens. 2013, 39, 382-395. [CrossRef]

39. Upper Silesia Nature Heritage Center. Available online: http://przyroda.katowice.pl/pl/ochrona-przyrody/ natura-2000/ostoje-siedliskowe/300-ostoja-olsztysko-mirowska (accessed on 10 May 2019).

40. Regional Directorate for Environmental Protection in Katowice, LFE11 NAT/PL/432 Protection of Valuable Natural Non-Forest Habitats Typical of the Orle Gniazda Landscape Park. Available online: http://lifezpkws. pl (accessed on 10 May 2019).

41. Baltsavias, E.; Gruen, A.; Eisenbeiss, H.; Zhang, L.; Waser, L.T. High-quality image matching and automated generation of 3D tree models. Int. J. Remote Sens. 2008, 29, 1243-1259. [CrossRef]

42. Congalton, R.G.; Green, K. Assessing the Accuracy of Remotely Sensed Data: Principles and Practices; CRC Press, Taylor \& Francis Group: Boca Raton, FL, USA; Abingdon-on-Thames, UK, 2008.

43. Powers, D.M.W. Evaluation: From Precision, Recall and F-Measure to ROC, Informedness, Markedness \& Correlation. J. Mach. Learn. Technol. 2011, 2, 37-63. 
44. Koga, Y.; Miyazaki, H.; Shibasaki, R. A CNN-based Method of vehicle detection from aerial images using hard example mining. Remote Sens. 2018, 10, 124. [CrossRef]

45. Stereńczak, K.; Będkowski, K.; Weinacker, H. Accuracy of crown segmentation and estimation of selected trees and forest stand parameters in order to resolution of used DSM and nDSM models generated from dense small footprint LIDAR data. Int. Arch. Photogramm. Remote Sens. Spat. Inf. Sci. 2008, 37, 27-32.

46. Straub, C.; Weinacker, H.; Koch, B. A fully automated procedure for delineation and classification of forest and non-forest vegetation based on full waveform laser scanner data. Int. Arch. Photogramm. Remote Sens. Spat. Inf. Sci. 2008, 37, 1013-1019.

47. Kane, V.R.; Gersonde, R.F.; Lutz, J.A.; McGaughey, R.J.; Bakker, J.D.; Franklin, J.F. Patch dynamics and the development of structural and spatial heterogeneity in Pacific Northwest forests. Can. J. For. Res. 2011, 41, 2276-2291. [CrossRef]

(C) 2019 by the authors. Licensee MDPI, Basel, Switzerland. This article is an open access article distributed under the terms and conditions of the Creative Commons Attribution (CC BY) license (http://creativecommons.org/licenses/by/4.0/). 